\title{
Key results on deep electrical conductivity anomalies in the Pannonian Basin (PB), and their geodynamic aspects
}

\author{
Ádám A. ${ }^{1}$, Szarka L. ${ }^{1}$, Novák A. ${ }^{1}$, Wesztergom V. ${ }^{1}$, \\ ${ }^{1}$ Geodetic and Geophysical Institute, Research Centre for Astronomy and Earth Sciences, \\ Hungarian Academy of Sciences, Sopron, H-9400 \\ adam@ggki.hu
}

\begin{abstract}
In the first part of the paper a brief introduction is given (a) to the magnetotelluric (MT) and magnetovariation (MV) soundings, (b) to electrical resistivity of minerals and rocks, and their dependence on temperature and fluid content. The basic geoelectric model in the Pannonian Basin is a (linear) tectonic zone ("dike") and a series of dikes.

In the second part the main crustal and mantle conductivity anomalies observed in the Pannonian Basin (PB) are summarized: (a) deep conductive crustal fractures and their relation to the occurrence of the earthquakes, boundary of the megablock(s) etc., (b) middle crustal conductors as indicators of decrease in stress and seismic activity depending on thermal regime, (c) the conductive asthenosphere and its lateral change in the PB in connection with the heat flow and tectonics. The general relation between the depth of the conductive asthenosphere and the regional heat flow is also presented, (d) MT anisotropy of the resistivity distribution in the $\mathrm{PB}$ and its tectonic explanation based on Haas's tectonic map (2001, Fig. 1). All these observations and conclusions are considered as results for further investigations.
\end{abstract}

\section{Introduction}

In the first part a brief introduction is given to the two basic methods of electromagnetic deep soundings: magnetotellurics and magnetovariation. Both methods allow studying the subsurface distribution of electric resistivity at depth, from the upper crust down to the upper mantle. The most characteristic conductivity anomalies from the practice of the Sopron magnetotelluric group will be summarized in details. The structural features of sedimentary basins, studied mainly by Eötvös Loránd Geophysical Institute (ELGI), and published e.g. by Nemesi, 2000) are not discussed here.

\subsection{Electromagnetic deep sounding - basic formulas}

The Earth's electromagnetic (geomagnetic and geoelectric) field variations penetrate to the subsurface, depending on the length of the time variations (i.e on the period T), and the electrical resistivity distribution at depth. The basic equations of the magnetotelluric (MT) sounding method were published by Tikhonov (1950) and Cagniard (1953) for a horizontally layered earth model. In magnetotelluric terminology it is called as "one-dimensional" (1D) case: the electrical resistivity varies exclusively with depth. Another important parameter, the induction vector was introduced nearly simultaneously by Parkinson (1959) and Wiese (1965). Its basic model is the so-called two-dimensional (2D) half-space, i.e. when the resistivity varies with the depth and one horizontal direction. These pioneering publications 
proved to be just a start signal of a huge theoretical, methodical and technical evolution, which led to a physically meaningful interpretation not only of one- and two-dimensional models, but also for three-dimensional geological situations, which are really close to reality (see e.g. Berdichevsky and Dimitriev, 2008). The MT and MV milestones were summarized among others by Ádám and Szarka (2011).

The basic MT and MV formulas are directly derivable from Maxwell's equations, assuming a plane-wave source, and electromagnetic diffusion processes at depth. In the classical magnetotellurics (MT) and its high-frequency - audio (AMT) and radio (RMT) - versions all resistivity- and depth information is contained in the so-called magnetotelluric impedance tensor $(\mathrm{Z})$. It operates as a transfer function between the horizontal electric (E) and magnetic (H) field components. The complex impedance elements, as a function of the period of the field ( $\mathrm{T}$, length of sinusoidal pulsations) are as follows:

$$
\begin{aligned}
& E_{x}(T)=Z_{x x}(T) H_{x}(T)+Z_{x y}(T) H_{y}(T) \\
& E_{y}(T)=Z_{y x}(T) H_{x}(T)+Z_{y y}(T) H_{y}(T)
\end{aligned}
$$

In case of the simplest $1 \mathrm{D}$ structure, i.e. the horizontally stratified half-space:

$Z_{x y}=-Z_{y x}, Z_{x x}=Z_{y y}=0$. In case of the basic $2 \mathrm{D}$ (strike and dip) directions: $Z_{x y} \neq Z_{y x}$, $Z_{x x}=Z_{y y}=0$. In a general 3D case, if the resistivity varies in all the three directions, each elements of the transfer function are nonzero and different from each other. The basic interpretation parameters in MT are the apparent resistivity (Rho) and the impedance phase $(\varphi)$. They are expressed as a function of the period $(T)$. Through the so-called skin depth concept, the resistivity and phase sounding curves are directly provide an "apparent" depth information. The "true" depth information needs so-called inverse (1D, 2D or 3D) modelling.

The length and the direction ("tipper") of the so-called induction vector are the basic interpretation parameters of the MV method. They are calculated from the complex transfer function between the vertical magnetic $\left(H_{z}\right)$ and the two mutually perpendicular horizontal magnetic components $\left(H_{x}\right.$ and $\left.H_{y}\right)$ vs. period. In the transfer equation:

$H_{z}(T)=X_{z x}^{(T)} H_{x}^{(T)}+X_{z y}^{(T)} H_{y}^{(T)}$

$X_{z x}$ and $X_{z y}$ are complex quantities. In the 1D case the length of the induction vector is zero. Aligned vector directions, combined with anti-symmetry indicate a two-dimensional character.

The wide spectrum of the variations of the electromagnetic field enables the determination of the MT resistivity values and MV resistivity changes from the surface to a depth of a few hundred $\mathrm{km}$.

\subsection{Electrical resistivity of the minerals and rocks}

The electrical resistivity values and their dependence on coordinates $\mathrm{x}, \mathrm{y}$ and $\mathrm{z}$ provide an indirect but indispensable information about the in situ physical state (temperature, pressure, fluid content) and composition of earth materials. The relationship between field geophysics and petrophysical interpretation is established through direct laboratory experiments. The resistivity of minerals and rocks in dry condition may easily span several powers of ten (Porstendorfer, 1975); the fluid content and the temperature (and together with the temperature, but inseparable from it: the pressure) have significant influence on the resistivity values. The role of the fluid in the resistivity is determined by the porosity of the rock and the quantity of the solved chemical material (electrolyte) as given by the so-called Archie law. The increasing temperature (and the pressure) with increasing depth will exponentially decrease the resistivity in the different modes of the semi-conduction. The temperature inside 
the Earth can be thus roughly estimated from the electrical resistivity itself. This effect was presented by Oelhoeft (1981). See Figure 2 for details.

Metallic minerals and graphite (graphitic rocks) have the lowest resistivity values. Tectonic lineaments are characterized in general by low resistivities due to the fluid and/or graphite content of disturbed zones. Their significance is directly related to tectonism: they seem to operate as some kind of smearing material, decreasing the viscosity and the stress, fostering the movement and collapse of the material, e.g. during earthquakes.

\subsection{Geoelectric model of linear tectonic zones (deep fractures, subducting plates, etc.)}

In order to be able to study real, complex tectonic zones, their main features should be concentrated into mathematically treatable geoelectric models. The simplest possible but already useful model is a conducting lineament (a "dike", shown in Fig. 3) in the lithosphere (which is assumed to be homogeneous) over a low-resistivity (conductive) asthenosphere. The dike represents a rock complex, loosed by tectonic movements, and having, as a consequence, an increased porosity. Its low resistivity is due to fluid or to other high-conductivity material such as graphite, which can be transported even by fluid.

The conductive dykes having a few $\Omega m$ resistivity are embedded in much more resistive rocks (e. g. $500 \Omega \mathrm{m}$ ). Such long tectonic lines (structures) are treated as two-dimensional (2D) models. The MT source field has two basic modes: TE mode (or E polarization, when the electric field is in strike direction), and TM mode (H polarization, when the electric field is in dip direction). In this way, beneath the measuring stations two main types of so-called pseudo-sections can be constructed as a function of the period-based pseudo-depth: TE and TM pseudo-sections, as shown in Figure 3.

In the TE mode the sources are currents, therefore in the TE pseudo-section the so-called induction side effect is dominating. In TM mode the sources are electric charges, appearing just at the resistivity inhomogeneity boundaries. This charge effect allows a better localization of such inhomogeneities than the induction side effect. The high-conductivity (low-resistivity) dikes are indicated in both polarizations by phase $(\varphi)$ values greater than $45^{\circ}$.

The next model is series of parallel lineaments (Ádám 2001). The basic ( $\mathrm{E}-$ and $\mathrm{H}$ polarization) MT anomalies are illustrated through Rho (apparent resistivity) and $\varphi$ (impedance phase) sounding curves over the centre of the system (Fig. 4). The conducting dikes are indicated only in $\mathrm{E}$ polarization (due to the summarized effect of current channeling), and they are not indicated in $\mathrm{H}$-polarization (due to the wipe-out effect of boundary charges). At longer periods the decreasing branch of the E- and H-polarization sounding curves refers to the high-conductivity asthenosphere. Both dike systems occur in PB as it will be illustrated.

\section{Upper crustal conductivity anomalies}

\subsection{Deep fractures between the Lake Balaton and Rába River, the so-called Transdanubian Conductivity Anomaly (TCA) and its relation to the earthquakes}

\subsubsection{Historical remarks}


Already in the early 1960's a conductivity anomaly (CA, called later as Transdanubian Conductivity Anomaly, TCA) was detected by relative telluric soundings (Ádám and Verö, 1964) and later by MT soundings (Takács, 1968) between Lake Balaton and Rába River. TCA served later as a field laboratory for methodological developments, including many experiments. In the region altogether nearly 300 MT soundings have been measured by different institutions. Ádám (2001) carried out a synthesis, Tátrai and Varga (2001) interpreted jointly MT and seismic data. Relation between the TCA and earthquakes were studied by Ádám and Zalai (2000), Glover and Ádám (2008) etc. A series of typical TE mode MT sounding curves are shown in Fig. 5 (Ádám and Varga, 1990).

\subsubsection{Present knowledge}

Under the thick Mesozoic carbonates three great tectonic lines (zones) could be separated in NE-SW direction, at a depth of 4-7 km, inverting all available MTS data, measured by the Sopron group and ELGI (Fig. 6). It is still questionable whether TCA consists of continuously conducting lineament structure (strike slip zones, fractures) or of separated conductors in the crossing of the longitudinal (NE-SW) and transversal (NW-SE) fractures. The anomaly system is well determined by the Wiese induction arrows (Fig. 7, Wallner, 1977) indicating the conductors with their minimum lengths. These conducting "lines" (strike slip zones) include three great earthquake occurrences (Berhida-Várpalota, Mór, Komárom).

It is probable that TCA played some role in generation of these earthquakes. The parameter used for the characterization of a conductor and its material is the summarized horizontal conductivity, the so-called conductance ( $S=\frac{\Delta h}{R h o}$ [siemens], where $\Delta h$ is the thickness of the conductor, Rho is its mean resistivity). The $\mathrm{S}$ value of a few dikes is higher than ten thousand siemens. Therefore it is probable that besides fluid, other high-conductivity earth materials, e.g. graphitic rocks may be also present in the conductors (in the fractures), accumulated by tectonics. This dike system corresponds to our theoretical model, shown in Fig. 4. The TE and TM mode sounding curves represent typical MT features. In the direction of tectonic lines generally the $R h o_{\min }$ or $\left(\rho_{\min }\right)$ values were taken as E-polarization ones. The lateral distribution of conductors are indicated also in the phase anomaly map (see Fig. 8). From the inversion of the MT sounding curves it is assumed that the dike system comes up from a high-conductivity layer.

Magnetotelluric soundings, near the greatest devastation area of the Berhida earthquake of 15 August 1985, detected a high-conductivity dike (Fig. 9). It is assumed, that the corresponding deep fracture, having low viscosity materials such as graphite at a depth of a few $\mathrm{km}$, influenced the outburst of the earthquake (Ádám and Zalai, 2000). This assumption is supported by the following observations: (1) the hypocentres of the earthquakes in NTransdanubia are about at the same depth as the sources of TCA (see its consequences in the paper by Glover and Ádám 2008, in connection with the behavior of graphite under pressuretemperature condition), (2) Zsíros (1985) found that the attenuation of the seismic waves in Hungary, coming from outside Hungary, is the highest in the TCA region.

\subsection{Geoelectric indication of the common great tectonic lines of the Alps and the Pannonian Basin}

In Fig. 11 the main tectonic lines are shown, which connect an Alpine region (Gail valley) and the Pannonian Basin (Transdanubia). In Austria they are the Insubric line and the 
Periadriatic line, and their continuations in Hungary are the Rába and Balaton lines. This latter one is the southern boundary of the megablock ALCAPA, and its southern unit is known as PELSO.

The Periadriatic line has been studied by long period MT soundings in its several different parts. The measuring area is shown in Fig. 10 by dotted squares (Ádám et al., 1986). Audiomagnetotellurics (AMT) detects more precisely the near-surface conductors (Ádám et al., 1992). An almost EW conductor along the Periadriatic line appears not only in the MT sounding curves, but also in the great increase of the magnetic variations of the NS magnetic field $\left(H_{x}\right)$ vs. period, compared to those of the same components measured in Nagycenk observatory (Verö, 1986; Fig. 11). In the geo-electromagnetic literature this phenomenon is called as "current channeling". The results of the audio-magnetotelluric (AMT) soundings are in a good agreement with aeromagnetic measurements and geologic mapping indicating graphitic lenses in the Paleozoic layers of the Gailtaler Alps (parallel with the Peridariatic lines).

As shown in Fig. 10, the continuation of Periadriatic line in Hungary is the Balaton line. The Balaton line as the southern boundary of the ALCAPA/PELSO megaunit is an important tectonic (fracture) zone filled by high-conductivity earth materials. It was detected in its eastern part by Varga (1980), and along the CEL-07 MT sounding profile, near the AustroHungarian border (Fig. 1, Szarka et al., 2005). The resistivity profile was computed from the inversion of 72 TE mode deep sounding curves (Fig. 12). In the 2D inversion of TE mode MT data, the effect of the Balatonfö line (in the axis of Lake Balaton) and of the Balaton line could not be separated from each other, obviously due to the induction side effect. The value of the conductance beneath the Balaton line is somewhere between 2000 and 3000 siemens. These values are much lower than the highest (at some stations close to ten thousand siemens) conductance values in the TCA region. The conductor's material is thought to be fluid (electrolyte). In a borehole, near the neighbourhood of the Balaton line, $\mathrm{CO}_{2}$ and $\mathrm{He}$ were detected, indicating earlier volcanic activities. The role of the graphite remains questionable.

In Fig. 12 TCA is shown in the northern part of the CEL-07 MT pseudosection. The ZágrábZemplén line is also visible here, as the northern border of the TISIA (TISZA) megablock. The Rába line can be followed by MT soundings, too (Nemesi et al., 1994), first of all at the northern border of the TCA.

\section{Middle crustal conductor}

According to a hypothesis (Hyndman and Shearer, 1989), the transition between the rigid and elastic state in the crust is due to dehydration processes (loss of a water molecule from the reacting molecule), taking place as a function of temperature, which depends on the local heat flow. Collecting the depth values of the middle/lower crustal conductors in different areas and the corresponding heat flow values, an empirical relation (Fig. 13) was derived by Ádám (1987). This conductor is weakly indicated by MT soundings in the area of Hungary. See also this conductor in Table 1 at somewhat shallower depth (at about $14 \mathrm{~km}$ ). Most data, characterizing Pannonian Basin, were derived from dense MT measurements carried out between Tiszaroff and Dévaványa (by the Hungarian oil company, in the 1980's). Smoothed apparent resistivity $\left(\rho_{a}\right)$ curves and their simplified inversion results (obtained by the socalled Bostick transformation) are shown in Fig. 14. The conducting layer in the lower crust was found at a depth of about $18 \mathrm{~km}$ (Ádám et al., 1989). Projecting this depth value to the 
focal depth distribution diagram in Hungary (Zsíros, 2000), it can be concluded that the conductor lies at the declining side (wing) of the earthquake occurrence values. The depth of the conductor well correlates also with the decrease of the lithospheric strength (Horváth and Cloething, 1996).

All the three effects: the increase of the conductivity, the decline of the seismic activity and of the strength may be the influence of dehydration process in the middle/lower crust, through increasing the rock (granite, basalt) water content. The hypothesis is worth keeping in mind.

\section{Asthenosphere}

\subsection{Upcoming asthenosphere in the Pannonian Basin}

It was thought already after the first wide band magnetotelluric soundings that the first conductive layer in the upper mantle, presumably corresponding to the asthenosphere, has an elevated position $(45-70 \mathrm{~km})$ in the Pannonian Basin, with respect to the surrounding platform areas (Ádám; 1963, 1965). Beneath the East European platform, the conductive asthenosphere is situated at a depth of greater that $200 \mathrm{~km}$, if it is really an asthenospheric layer. (See later Vanyan et al., 1977). This large depth difference could be explained by a temperature difference in the Earth's interior below the Neogene Pannonian Basin and the Variscan and Precambrian areas (expressed by the surface heat flow), and also by the temperature dependence of electric semi-conduction. In the Pannonian Basin, both seismology (Bisztricsány, 1974) and active seismics (Posgay, 1975) found Gutenberg's asthenosphere and the Low Velocity Layer (LVL) in the same depth interval.

An unambiguous magnetotelluric identification of deep conducting layers might sometimes be extremely difficult, due to various near-surface inhomogenities. These distortions are partly caused by the relief or tectonics of the basement, which have some regional characteristics, appearing in the MT anisotropy (Ádám, 1969). In studying upper mantle, the distorting effect of the conducting zones in the whole crust must be taken into account, even outside of the boundary of the anomaly.

The characteristic period range of the first conducting zone in the upper mantle is $400<T<$ 2000 s here. In Fig. 15 typical TE mode deep MT sounding curves from the Pannonian Basin are shown together with "the normal resistivity profile" (Vanyan et al., 1977), characterizing the resistivity decrease in stable shield area due to the monotonous increase of the temperature, and without partial melting (without the asthenosphere). There the apparent resistivity is higher by one or two orders of magnitude than in the Pannonian Basin. Layer sequences corresponding to the MT sounding curves shown in Fig. 15 are presented in Table 1, after Ádám et al. (1982). According to these soundings, in the Pannonian Basin the depth of the asthenosphere is around $46-66 \mathrm{~km}$.

2D geoelectric sections constructed along the international geotraverse No VI (crossing the Pannonian Basin, the W-Carpathians and the Bohemian Massif, Červ et al., 1987), and No III (crossing the Eastern Carpathians towards to East-European Platform with isotherm $\mathrm{T}=$ $1300^{\circ}$, Zhdanov et al., 1986) clearly show the deepening of the asthenosphere from the Pannonian Basin towards the older tectonic units, in connection with the decrease of the heat flow (Fig. 16). The two profiles are shown in the figure. 
The most complete high-conductivity structure of the crust and mantle is indicated by the deepest MT sounding in the Pannonian Basin measured at the Nagycenk observatory, lying above a $1500 \mathrm{~m}$ thick sediment of low resistivity (Fig. 17). The $S_{q}$ variation and its harmonics were also applied to determine these sounding curves (Ádám et al., 1981). As the anisotropy is low and there is no static shift due to changes in the sediment thickness, the extreme values of the resistivity $\left(\rho_{\max }\right.$ and $\rho_{\min }$ ) give practically the same values for the depth of the asthenosphere: $78 \mathrm{~km}$ and $83 \mathrm{~km}$. For the depth of the phase transition $298 \mathrm{~km}$ and $308 \mathrm{~km}$ were obtained. These values are certainly a little distorted. The top of the asthenosphere fits well to other MT measurements in the Pannonian Basin (see Table 1), although Nagycenk observatory lies at the rim of the hot basin. It explains its somewhat higher value than the average. See more details in the next chapter.

\subsection{Map of the depth of the asthenosphere in the Pannonian Basin (Fig. 18)}

For the construction of the asthenospheric depth only those MT stations were taken into account, where reliable asthenospheric depth could be calculated by using 1D inversion from both extreme curves (i.e. $\rho_{\max }$ and $\rho_{\min }$ ). Since decomposition did not bring any essential change in the parameters of the asthenosphere, primarily the static shift effect was corrected. As a next step, the geometric mean values of the asthenospheric depth, derived from $\rho_{\max }$ and $\rho_{\min }$ curves, were considered for mapping. A depth step of $10 \mathrm{~km}$ was chosen. This value corresponds to the uncertainty of the determination. The map shows an average depth of 55$65 \mathrm{~km}$ in the centre of the basin. This large area is embraced by a belt of $65-75 \mathrm{~km}$ depth range, which contains sites with asthenospheric depth of $75-85 \mathrm{~km}$ as well, i.e. the asthenosphere continuously deepens when moving away from the centre of the Pannonian Basin.

Inside the central part of the basin extensional sub-basins were found. One of them is the Békés one, where the asthenosphere seems to be at somewhat smaller depth than $60 \mathrm{~km}$ (assuming the effect of the thick sediments has been correctly eliminated). The Békés subbasin is characterized by a high gravity anomaly, indicating a high-density intrusion in the crust, as consequence of its extension. The tectonic model of the Békés sub-basin is approximated by Buck's rift model. In the southern part of the PGT-1 profile (Fig. 19) 2D magnetotelluric inversion indicate higher position of the asthenosphere (Fig. 20, Ádám et al, 1996).

Posgay et al. (1995) corrected the heat flow values measured at the surface in the Békés subbasin for steady-state condition. In this way he obtained much higher values than the measured ones. This conclusion, together with seismic results (Posgay et al., 1995) implies the upwelling of the asthenosphere, in agreement with Ádám's (1978) empirical relationship between heat flow and asthenospheric depth.

Besides the extensional sub-basins in the Great Hungarian Plain, an upwelling of the asthenosphere appears in the south-western part of the country, in the so-called Dráva subbasin, too.

It is obvious that the uncertainty of the magnetotelluric parameters increases with the depth of the target to be studied. It is due primarily to near-surface inhomogeneities, which may distort even the asthenospheric depth in very different manner, as was presented. Available corrections used in our case (decomposition, static shift) could only roughly improve the data. 
Nevertheless, the following earlier statements concerning the conductive asthenosphere have been confirmed:

- The average depth of the asthenosphere within the Pannonian Basin at 60-65 km, and is in agreement with the regional heat flow values $\left(\sim 100 \mathrm{~mW} / \mathrm{m}^{2}\right)$,

- Departing from the centre of the basin toward the Carpathians, the asthenospheric depth increases. It reaches about $80 \mathrm{~km}$ at the western border of the country toward the Eastern Alps as well,

- In the extensional deep sub-basins, especially in the Békés sub-basin, there is an upwelling of the asthenosphere to about $50 \mathrm{~km}$. There is a similar upward deformation in the MOHO and the lower crust, as found by the Posgay et al. (1995) deep seismic measurements,

- The average resistivity of the asthenosphere is, in the case of $\rho_{\min }$ curves, $\sim 16 \Omega \mathrm{m}$. This value accounts for a partial melting of only a few percent at the base of the lithosphere (Shankland and Waff, 1977).

\subsection{The surface heat flow as a systematizing parameter concerning the asthenospheric depth}

The relationship between the electrical conductivity and the temperature enables (see e.g. Uyeda and Rikitake, 1970) that MT data on the asthenospheric depth can be systematized according to a surface geoelectric parameter, characterizing the inner thermal state of the Earth.

Pollack and Chapman (1977) showed empirically that about $60 \%$ of the average surface heat flow origins from the upper mantle. If this is true, the surface heat flow is a proper quantity to analyze the thermal effects in the distribution of the electrical conductivity in the upper mantle, too, assuming a state of equilibrium.

The estimated MT data on depth of the conductivity increase in the asthenosphere (denoted by ICL (Intermediate Conducting Layer) as a hint to its situation between conducting zones in the Earth) arranged according to the regional heat flow yielded an empirical formula for the dependence of this depth on the heat flow (Ádám, 1978):

$$
h_{I C L}=155 q^{-1.46} \text {, where } \mathrm{q} \text { is given in old HFU (Heat Flow Unit } \approx 42 \mathrm{mWm}^{-2} \text { ). }
$$

As Fig. 21 shows, the depth values for $q<1 \mathrm{HFU}$ lie well above the $h_{I C L}>200 \mathrm{~km}$. Investigation was carried out besides the depth of the conducting zones to its conductivity. It has been generally found that in the asthenosphere $\varrho=10 \Omega \mathrm{m}\left(\sigma=\frac{1}{\rho}=0.1 \mathrm{Sm}^{-1}\right)$, e.g. beneath the Nagycenk observatory. Vanyan et al. (1977) gave also the value of $\varrho=10 \Omega \mathrm{m}$ for the conductivity of a well-developed asthenosphere in the other areas.

\section{Magnetotelluric anisoptropy of the deep sounding curves in the Pannonian Basin}

If one looks at the deep sounding curves (e.g. those measured in the area of the TCA in Fig. 6 ), it becomes obvious that the layer parameters could be very differently calculated from the extreme MT curves $\left(\rho_{\min }, \rho_{\max }\right)$. The cause of the difference origins from the inhomogenity and anisotropy of mineral and rock distribution in the Earth. The main organizing factor is the 
tectonics. The tectonic lines in the Pannonian Basin (Fig. 1) have two main directions: NESW and NW-SE, in connection with the evolution of the Pannonian Basin. The tectonic lines as conducting fractures draw out the MT sounding curves to become extreme. The $\rho_{\text {min }}$ values are measured in the strike direction and $\rho_{\max }$ values in deep direction (See conducting dike system in Figs. 3-4).

To get appropriate layer parameters, tensor invariants were proposed at first by Berdichevsky (1968). Szarka and Menvielle (2000) demonstrated that in the impedance tensor seven independent scalar invariants can be defined, and they provided their several possible systematizations. Novák (2010) provided a systematic field study, by using invariants. The simplest invariants are the (1) the sum of the main impedances $\left(Z_{x y}\right.$ and $\left.Z_{y x}\right),(2)$ the socalled determinant $\rho_{d e t}=\sqrt{Z_{x y} Z_{y x}+Z_{x x} Z_{y y}}$. This latter reduces in $2 \mathrm{D}$ case to $\rho_{d e t}=$ $\sqrt{Z_{x y} Z_{y x}}$. The efficiency of this simple geometric mean is illustrated in Table 2. (They are from Ádám's (1969) very early dataset on the approximate depth of the asthenosphere. They show that the geometric mean can give an appropriate value for the layer parameters too, derived from the impedance elements.

The average depth of the asthenosphere suits well to a much greater collection of data in the Pannonian Basin, i.e. to $60 \mathrm{~km}$. Of course, 2D and 3D modeling could somewhat refine the solutions. First of all, a much larger dataset would be needed reduce the uncertainties in the layer structure.

\section{Conclusions}

The main conclusions from the magnetotelluric (MT) deep soundings obtained in the Pannonian Basin are as follows:

(1) The MT soundings discovered significant tectonic lines as fractures, strike slip zones, boundary of megablocks (ALCAPA, TISZA), having conductive material (with great porosity filled by water solution, graphitic rocks, metallic minerals etc.). The most characteristic anomaly is the Transdanubian Conductivity Anomaly (TCA),

(2) In NW Transdanubia there is a relationship between conductors (CA) and earthquakes (their generation, attenuation, etc.)

(3) Heat-flow related effect of the temperature on the resistivity of semiconductor rocks at depth appears:

- in the middle/lower crustal conductivity anomaly as supposed to be due to dehydration process, decreasing the strain and seismic activity, too (at a depth of about $\sim 18 \mathrm{~km}$ ),

- in partial melting in the asthenosphere, enabling the indication of its boundary in the upper mantle (the average depth in the PB has been found to be $60 \mathrm{~km}$ ),

(4) As both the inhomogeneity and anisotropy of the rocks influence the resistivity distribution measured by MT soundings, structural information can be drawn from MT dataset, but at the same time it needs great attention in the data interpretation (using 2D and 3D modelings, tensor invariants, phase ellipses, etc.)

As a summary: from the MT soundings carried in the Pannonian Basin, several new tectonic (structural), physical and geological knowledge mosaics could be obtained. They either support or supplement (sometimes falsify) knowledge obtained from other geophysical 
techniques and led to new basic indications. At the same time, these results mean a foundation for future deep electromagnetic and other geophysical investigations. 


\section{Figure captions}

Fig. 1 Pretertiary structural units of Hungary and depth to the pretertiary basement (Haas, 2001)

Fig.2 Summary plot of the best available estimate of the electrical resistivity of granites versus temperature, pressure and water content. The dashed lines are for various water pressures in $\mathrm{MPa}$ for water salinities less than 0.1 molar $\mathrm{NaCl}$ (Olhoeft, 1981)

Fig. 3 Resistivity $(\rho)$ and phase $(\varphi)$ pseudo-sections of a conducting dike in $E$ and $H(B)$ polarizations (Ádám, 1987)

Fig. 4 A parallel dike system and its MT sounding curves ( $\rho$ and $\varphi$ ) in E and H(B) polarizations in its central part, including the effect of a conducting asthenosphere (Ádám, 2001)

Fig. 5 Long period (deep) MT curves measured in the TCA area (around town Mór; Ádám and Varga, 1990): (a) apparent resistivity ( $\rho$ ) vs period (T); (b) phase ( $\varphi$ ) curves vs. period (T). Error bars of $\varphi$ are shown separately for M-41

Fig. 6 Illustration of PB conducting dikes (large dots) along the NW-SE MT profiles. (Small dots are measuring sites). The resistivity sections of the dikes were obtained by using inversion (Ádám, 2001)

Fig. 7 Geomagnetic induction vectors measured in the TCA area (Wallner, 1977). The vectors are strongly reduced in the NE-SW conducting zones. Vector directions are influenced by NW-SE conducting fractures (Arora and Ádám, 1992)

Fig. 8 A qualitative image of conductivity structures calculated on basis of phase values belonging to the $\rho_{\min }$ values at period $(\mathrm{T})=500 \mathrm{~s}$. The high phase values $\left(>45^{\circ}\right)$ indicate the conductive bodies (Ádám, 2001)

Fig. 9 MT pseudo-section through the Berhida earthquake area, indicating a significant electrical conductor (blue) near the hypocentre

Fig. 10 Tectonic setting of the Transdanubian Central Range and high conductivity zones (stippled). Dotted squares indicate the MT measuring sites in the Alps. The inset shows the electric structure along the profile A-B by ELGI. Stippled lines give the position of good conductors (Horváth et al, 1987).

Fig. 11 Ratio of N-S magnetic variation $\left(\mathrm{H}_{\mathrm{x}}\right)$ amplitudes vs. period, calculated between amplitudes at Alpine measuring sites (see Fig. 11) and at the Nagycenk observatory (original figure of Verö (1986) not published, with permission of the author).

Fig. 12. Resistivity distribution along the CEL-07 profile (see in Fig. 1), on basis of inversion of 72 E-polarization $\left(\rho_{\text {min }}\right)$ deep sounding curves (Szarka et al., 2005)

Fig. 13 Empirical relation between the depth of middle crustal conductor and average heat flow of the areas (Ádám, 1987) 
Fig. 14 Smoothed $\rho_{\mathrm{a}}$ curves and their Bostick transformation measured between Tiszaroff and Dévaványa (Ádám et al., 1989

Fig. 15 Typical E-polarization MT sounding curves from the PB with Vanyan et al.'s (1977) "Normal Resistivity Profile"

Fig. 16 Geoelectric models of internal structures along geotraverse No VI, through WesternCarpathians (A) (Červ et al., 1984) and No III (B) through the Eastern-Carpathians with isotherm of $1300 \mathrm{C}^{\circ}$ (Zhdanov et al., 1986). Profiles A and B see in the map

Fig. 17 MT sounding curves measured in the Nagycenk observatory (Ádám et al., 1981)

Fig. 18 Map of the asthenospheric depth based on the geometric mean of the depth values derived from $\rho_{\max }$ and $\rho_{\min }$ curve (Ádám and Wesztergom, 200

Fig. 19 Map of the PGT-1 deep MT and seismic profiles in the Great Hungarian Plain with isolines of the basement depth

Fig. 20 Resistivity distribution beneath profile PGT-1 as results of 2D OCCAM inversion of the MT $\rho_{\text {min }}$ deep sounding curves (Ádám et al., 1996)

Fig. 21 Dependence of the MT asthenospheric depth on the regional heat flow (Ádám, 1978)

Table 1: Layer sequences corresponding to MT sounding curves shown in Fig. 18 (Ádám et al., 1982)

\begin{tabular}{|c|c|c|c|c|c|}
\hline \multicolumn{3}{|c|}{ No 1} & \multicolumn{3}{|r|}{ No 3} \\
\hline layer & $\begin{array}{c}\text { thickness } \\
\mathrm{h} \mathrm{km}\end{array}$ & $\begin{array}{c}\text { resistivity } \\
\Omega \mathrm{m}\end{array}$ & layer & $\begin{array}{c}\text { thickness } \\
\mathrm{h} \mathrm{km}\end{array}$ & $\begin{array}{c}\text { resistivity } \\
\Omega \mathrm{m}\end{array}$ \\
\hline 1 & 0.50 & $5.00 \mathrm{~S}_{1}=100 \Omega^{-1}$ & 1 & 1.20 & $1.70 \mathrm{~S}_{1}=705.9 \Omega^{-1}$ \\
\hline 2 & 10.00 & 300.00 & 2 & 14.00 & 70.00 \\
\hline 3 & 0.12 & $0.10 S_{3}=1200 \Omega^{-1}$ & 3 & 0.70 & $1.00 \mathrm{~S}_{3}=700 \Omega^{-1}$ \\
\hline 4 & 40.00 & 60.00 & 4 & 25.00 & 50.00 \\
\hline 5 & 15.00 & 15.00 & 5 & 25.00 & 15.00 \\
\hline \multirow[t]{2}{*}{6} & \multirow{2}{*}{\multicolumn{2}{|c|}{$\mathrm{H}=65.5 \mathrm{~km}$}} & 6 & & 5.00 \\
\hline & & & \multicolumn{3}{|r|}{$\mathrm{H}=65.9 \mathrm{~km}$} \\
\hline \multicolumn{3}{|c|}{ No 2} & \multicolumn{3}{|r|}{ No 4} \\
\hline 1 & 0.50 & $5.00 \mathrm{~S}_{1}=100 \Omega^{-1}$ & 1 & 1.00 & $1.20 \mathrm{~S}_{1}=833 \Omega^{-1}$ \\
\hline 2 & 9.00 & 300.00 & 2 & 14.00 & 45.00 \\
\hline 3 & 0.19 & $0.10 S_{3}=1900 \Omega^{-1}$ & 3 & 0.80 & $1.00 S_{3}=800 \Omega^{-1}$ \\
\hline 4 & 45.00 & 200.00 & 4 & 30.00 & 100.00 \\
\hline 5 & & 5.00 & 5 & & 4.00 \\
\hline \multicolumn{3}{|c|}{$\mathrm{H}=54.7 \mathrm{~km}$} & \multicolumn{3}{|r|}{$\mathrm{H}=45.00 \mathrm{~km}$} \\
\hline
\end{tabular}


Table 2:

Efficiency of the simple geometric mean on the determination of the depth of the asthenosphere (Ádám', 1969)

\begin{tabular}{|l|c|c|c|}
\hline \multirow{2}{*}{ Station with abbreviation } & \multicolumn{3}{|c|}{ Depth of the asthenosphere } \\
\cline { 2 - 4 } & $h_{\rho_{x}}$ & $h_{\rho_{y}}$ & $\sqrt{h_{\rho_{x}} h_{\rho_{y}}}$ \\
\hline Nagycenk (N) & 100 & 50 & 70 \\
\hline Tihany (T) & 55 & 37 & 45 \\
\hline Baja (B) & 65 & 40 & 51 \\
\hline Gabčikovo & 80 & 30 & 49 \\
\hline GEAB-II (Túrkeve) (G) & 100 & 30 & 54 \\
\hline Vezseny (V) & 80 & 40 & 56 \\
\hline Endröd (E) & 70 & 100 & 83 \\
\hline Gyula (G) & 100 & 55 & 74 \\
\hline Average depth: & & & 60.25 \\
\hline
\end{tabular}




\section{References}

Arora B. R. and Ádam A. (1992): Anomalous directional behavior of induction arrows above elongated conductive structures and its possible causes. Phys. Earth Planet Int., 74 (34). $183-190$.

Ádám A. (1963): Study of the electrical conductivity of the Earth's crust and upper mantle. Methodology and results (in Hungarian). Dissertation, Sopron, $111+X L V$

Adam A. (1965): Einige Hypothesen Über den Aufbau des oberen Erdmanteles in Ungarn, Gerlands Beitr. Geophys., 74, 20-40.

Ádám A. (1969): Appearance of the electrical inhomogeneity and anisotropy in the results of complex electrical exploration of the Carpathian Basin. Acta Geod. Geoph. Mont. Hung. 4 (1-2), 187-197.

Ádám A. (1978): Geothermal effects in the formation of electrically conducting zones and temperature distribution in the Earth. Phys. Earth Planet Int. 17, 21-25.

Ádám A. (ed.) (1976): Geoelectric and Geothermal Studies. KAPG Geophysical Monograph, Akademiai Kiadó, pp. 752.

Ádám A. (1987): Are there two types of conductivity anomaly (CA) caused by fluid in the crust. Phys. Earth Planet Int. 15, 209-215.

Ádám A. (1987): Tectonic effects in the magnetotelluric field and their numerical modelling, Gerlands Beit. Geophysik, 96, 17-31.

Ádám A. (1993): Physics of the upper mantle. A review. Acta. Geod. Geoph. Mont. Hung. 28 (1-2), 151-195.

Ádám A. (2001): Relation of graphite and fluid bearing conducting dikes to tectonics and seismicity (Review on the Transdanubian crustal conductivity anomaly). Earth Planets Space 53, 903-918.

Ádám A.,Varga G.,(1990): Distortions of electromagnetic field in shallow basins and near resistive outcrops. Phys. Earth Planet. Int. 60, 80-85

Ádám A. and Verő J. (1964): Ergebnisse der regionalen tellurischen Messungen in Ungarn. Acta Technica, 47, 761-773.

Ádám A., Märcz F., Verő J., Wallner Á., Duma G., Gutdeutsch R. (1981): Magnetotelluric sounding in the Transitional Zone between the Eastern Alps and Pannonian Basin. $J$. Geophys. 50, 37-44.

Ádám A., Verő J., Cz. Miletits J., Holló L., Wallner A. (1981): The Geophysical Observatory near Nagycenk I. Electromagnetic measurements and processing of data. Acta Geod. Geopy. Mont. Acad. Sci. Hung., 16 (2-4), 333-351. 
Adam A., Vanyan L. L., Varlamov D. A., Yegorov I. V., Shilovski A. P., \& Shilovski P. P. (1982): Depth of crustal conducting layer and asthenosphere in the Pannonian basin determined by magnetotellurics. Phys. Earth Planet Int. 28 (3), 251-260.

Ádám A., Duma G., Gutdeutsch R., Verő J., Wallner Á. (1986): Periadriatic lineament in the Alps studied by magnetotellurics. J. of Geophysics, 59, 103-111.

Ádám A., Landy K., Nagy Z. (1989): New evidence for distribution of the electric conductivity in the Earth's crust and upper mantle in the Pannonian Basin as a „hotspot”. Tectonophysics 164, 361-368.

Ádám A., Duma G., Berger J., Horváth J. (1992): Tectonic and geoelectrical features of the Periadriatic lineament (S-Austria) with a generalization. In: Ádám A. ed. Electromagnetic results in active orogenic zones. Special Issue of the IAGA Symposium 1.8. August 1991, Vienna. Acta Geod. Geoph. Mont. Hung., 27, 47-64.

Ádám A., Szarka L., Prácser E., Varga G. (1996): Mantle plumes or EM distortion in the Pannonian Basin? (Inversion of the deep magnetotelluric (MT) soundings along the Pannonian Geotraverse). Geophysical Transactions 40(1-2), 45-78.

Ádám A. and Zalai P. (2000): Geoelectric model of the tectonics in the area of the Berhida earthquake, Magyar Geofizika, 41(2), 60-74, (in Hungarian).

Ádám A., Wesztergom V. (2001): An attempt to map the depth of the electrical asthenosphere by deep magnetotelluric measurements in the Pannonian Basin (Hungary). Acta Geol. Hung. 44(2-3), 167-192.

Ádám A., Szarka L. (2011): Geoelectromagnetism. In: Gupta, H.K. (ed.), Encyclopedia of Solid Earth Geophysics. Springer, 341-352.

Berdichevsky M.N. and Dmitriev V.I. (2008): Models and methods of magnetotellurics: Springer-Verlag, Berlin, Heidelberg, pp. 563.

Buck W.R. (1991): Modes of continental lithospehre extension. J. Geophys. Res. 96, 20161 20187.

Cagniard L. (1953): Basic theory of the magneto-telluric method of geophysical prospecting: Geophysics, 18, 605-635.

Červ V., Pek J. and Praus O. (1987): Numerical modelling of geoelectrical structures in Czechoslovakia. Phys. Earth Planet Int., 45, 170 - 178.

Glover P.W. and Ádám A. (2008): Correlation between crustal high conductivity zones and seismic activity and the role of carbon during shear deformation. J. Geophys, Res. 113., B12210 doi 10.1029/2008JB005804.

Horváth F., Ádám A. and Stanley W.S. (1987): New geophysical data: evidence for the allochthony of the Transdanubian Central Range. Rend. Soc. Geol. It., (1986) 9, 123 130 . 
Horváth F. and Cloething S. (1996): Stress induced late stage subsidence anomaly in the Pannonian Basin. Tectonophysics 266, 287-300.

Hyndman R. D. and Shearer P. M. (1989): Water in the lower continental crust: modelling magnetotelluric and seismic reflection results. Geophysical Journal International, 98, 2, 343.

Nemesi L. (2000): Telluric map of Transdanubia. Geophys. Transactions, 43, 115-120.

Nemesi L., Hobot J., Kovácsvölgyi S., Milánkovich A., Pápa A., Stomfai R., Varga G. (1994): Investigation of the basin basement and crust structure beneath the Kisalföld (performed in ELGI between 1982 and 1990). Geophysical Transactions Vol. 39. No. 23., 193-223 (in Hungarian).

Novák A. (2010): Electromagnetic imaging in geophysics with tensor invariants from the near surface to Transdanubian deep structures. PhD dissertation (in Hungarian), Sopron (Hungary), 187.

Olhoeft G. (1981): Electrical properties of granite with implications for the lower crust. Journal of Geophysical Research, 86, 931-936.

Parkinson W. D. (1959): Direction of rapid geomagnetic fluctuations. Geophys. J. Astr. Soc. 2, 1-14.

Pollack H. N. and Chapman D. S. (1977): On the regional variation of heat flow, geotherms, and lithospheric thickness. Tectonophysics, 38(3-4), 279-296.

Porstendorfer G. (1975): Principles of Magneto-telluric Prospecting. Gebrüder Borntraeger. Berlin West, Stuttgart, pp. 118.

Posgay K., (1975): Mit Reflexionsmessungen bestimmte Horizonte und Geschwindigkeitverteilung in der Erdkruste und im Erdmantle. Geophys. Trans. 23, 1318 .

Posgay K., Bodoky T., Hegedűs E., Kovácsvölgyi S., Lenkey L., Szafián P., Takács E., Tímár Z., Varga G. (1995): Asthenospheric structure beneath a Neogene basin in southeast Hungary. Tectonophysics, 252, 467-484.

R. Tátrai M., Varga G. (2001): Newest data about the deep structure of the Kisalföld and the Transdanubian Cetral Range (in Hungarian). Magyar Geofizika, 42, 22-35.

Shankland T.J. and Waff H.S. (1977): Partial melting and electrical conductivity anomalies in the upper mantle. J. Geophys. Res. 82, 5409-5417.

Szarka L., Ádám A., Kiss J., Madarasi A., Novák A., Prácser E., Varga, G. (2005) Magnetotelluric images from SW-Hungary, completed with gravity, magnetic and seismic measurements. $17^{\text {th }}$ International Workshop on Electromagnetic Induction in the Earth-Hyderabad, India. Abstracts. 
Szarka L.and Menvielle M. (1997): Analysis of rotational invariants of magnetotelluric impedance tensor. Geophysical Journal International 129, 133-142.

Takács E (1968): Anomalous conductivity of the upper crust in the NW foreground of the Bakony mountains. Acta Geod. Geoph. Mont. Hung., 3, 155-160.

Tikhonov A. N. (1950): On the determination of electric characteristics of deep layers of the Earth's crust, Dokl. Aad. Nauk. SSSR 73, 295-297.

Vanyan L.L., Berdichevsky M.N., Fainberg E.B. and Fiskina M.V. (1977): The study of the asthenosphere of the East European Platform by electromagnetic sounding. Phys. Earth Planet. Inter., 14: Pl-P2.

Uyeda S. and Rikitake T. (1970): Electrical conductivity anomaly and terrestrial heat flow. $J$. Geomagn. Geoelectr., 22, 75-90.

Varga G. (1980): Geophysical investigation of geological basic profiles I. Report on the telluric and MT measurements. MÁELGI, Manuscript (in Hungarian).

Verö J. (1986): On the relative amplitudes of $\mathrm{N}-\mathrm{S}\left(\mathrm{H}_{\mathrm{x}}\right)$ geomagnetic variations measured in 3 stations in the Gaitaler Alps referred to those observed in the Nagycenk Observatory (Hungary) vs. period (not published data).

Volarovich M.P., Parkhomenko F.I. (1976): Electrical Properties of Rocks at High Temperatures and Pressures. In A. Ádám (Ed.), Geoelectric and Geothermal Studies. KAPG Geophysical Monograph. Akadémiai Kiadó, Budapest, 321-362.

Wallner Á. (1977): The main features of the induction arrows in the area of the Transdanubian conductivity anomaly. Acta Geod. Geoph. Mont. Hung., 12, 145-150.

Wiese H. (1965): Geomagnetische Tiefentellurik. - Abh. Geomagnet. Institut Potsdam 36: 5146.

Zsíros T. (1985): An Estimation of Seismic Hazard in Hungary. Gerlands Beitr. Geophysik 94, 111-122.

Zsíros T. (2000): Seismicity of the Carpathian Basin and earthquake hazard. Hungarian Earthquake Catalogue (456-1995) (in Hungarian). Edited by the Director of GGRI, J. Závoti, pp. 495. 
Figures

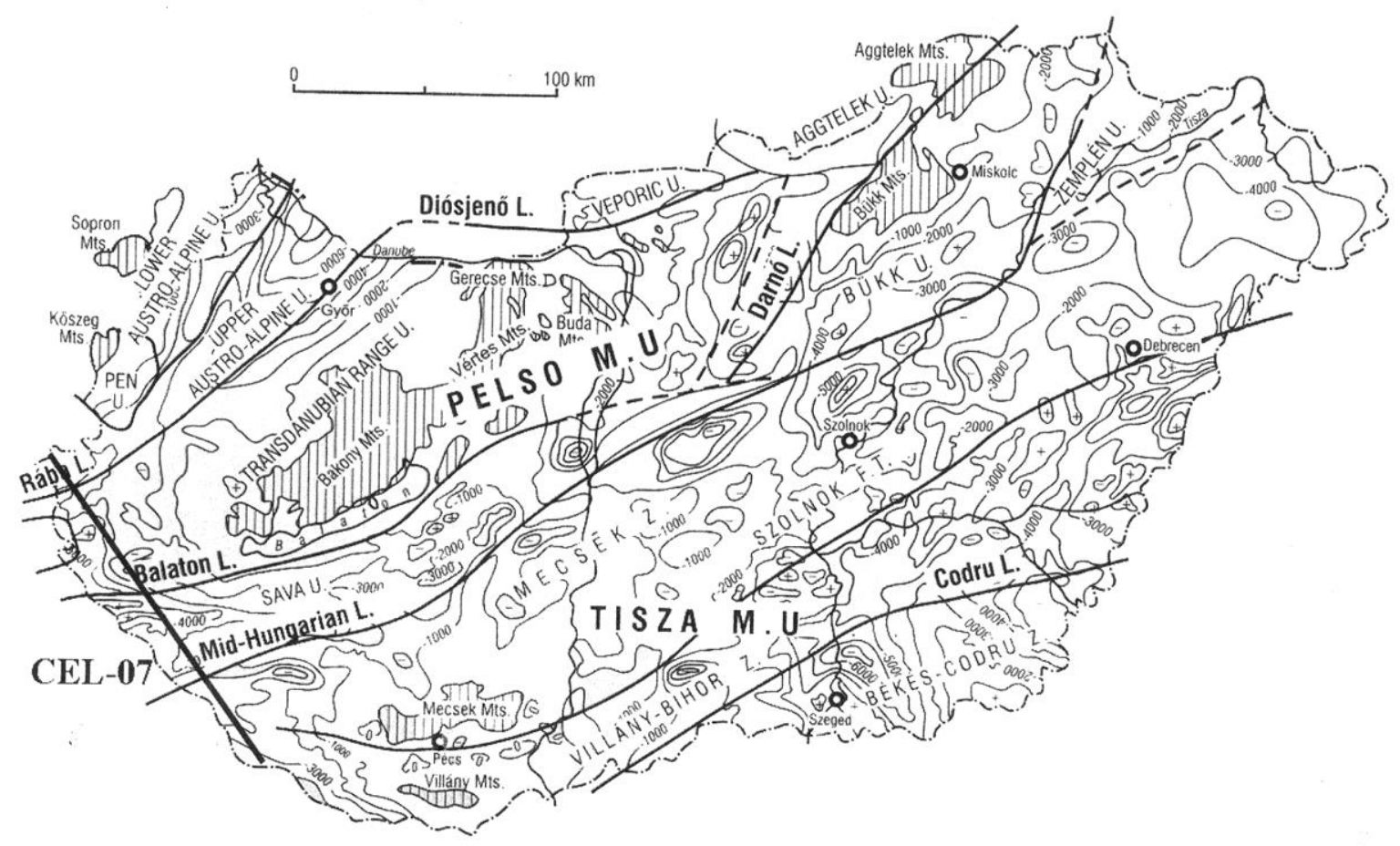

Fig. 1.

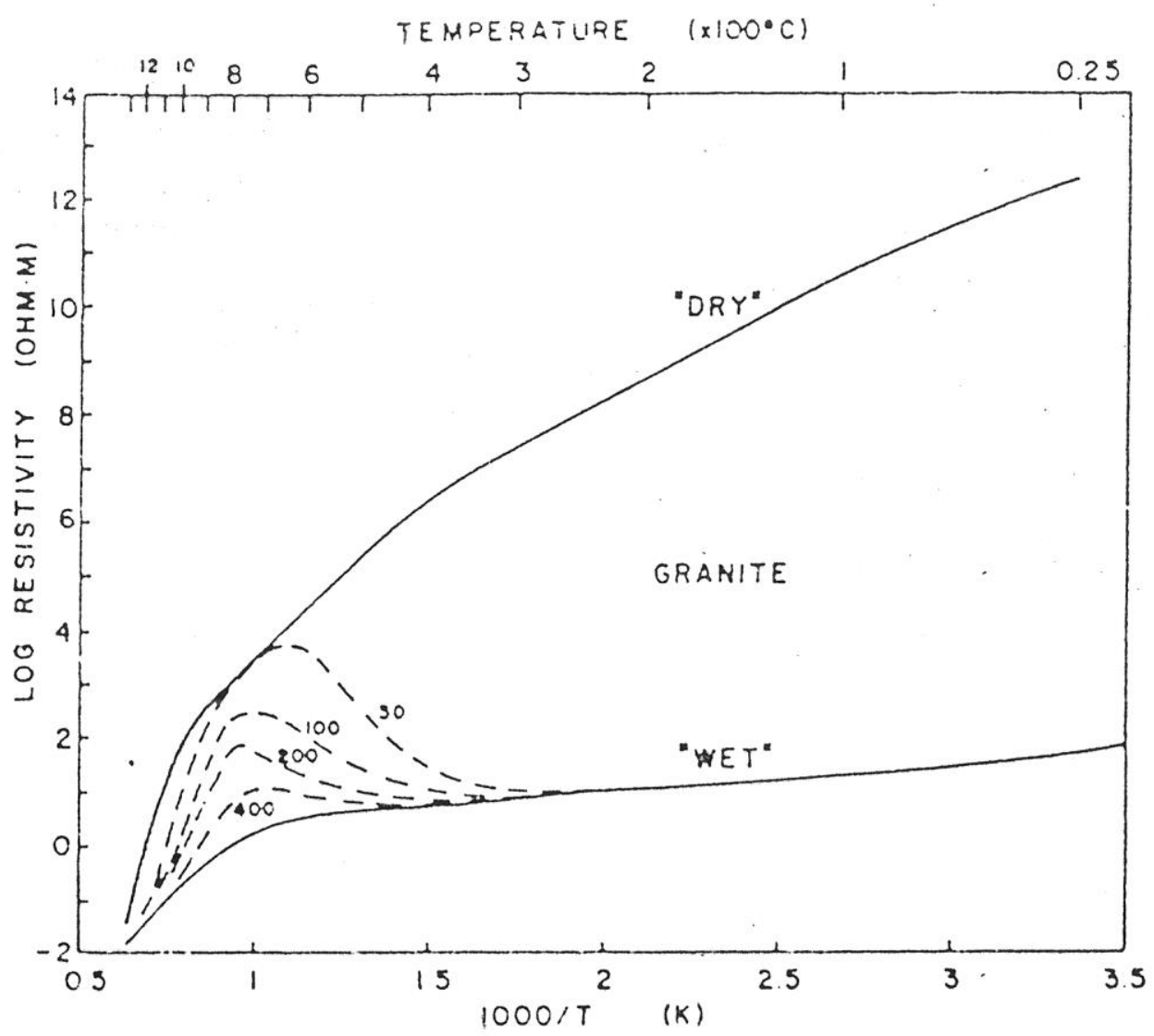

Fig. 2. 

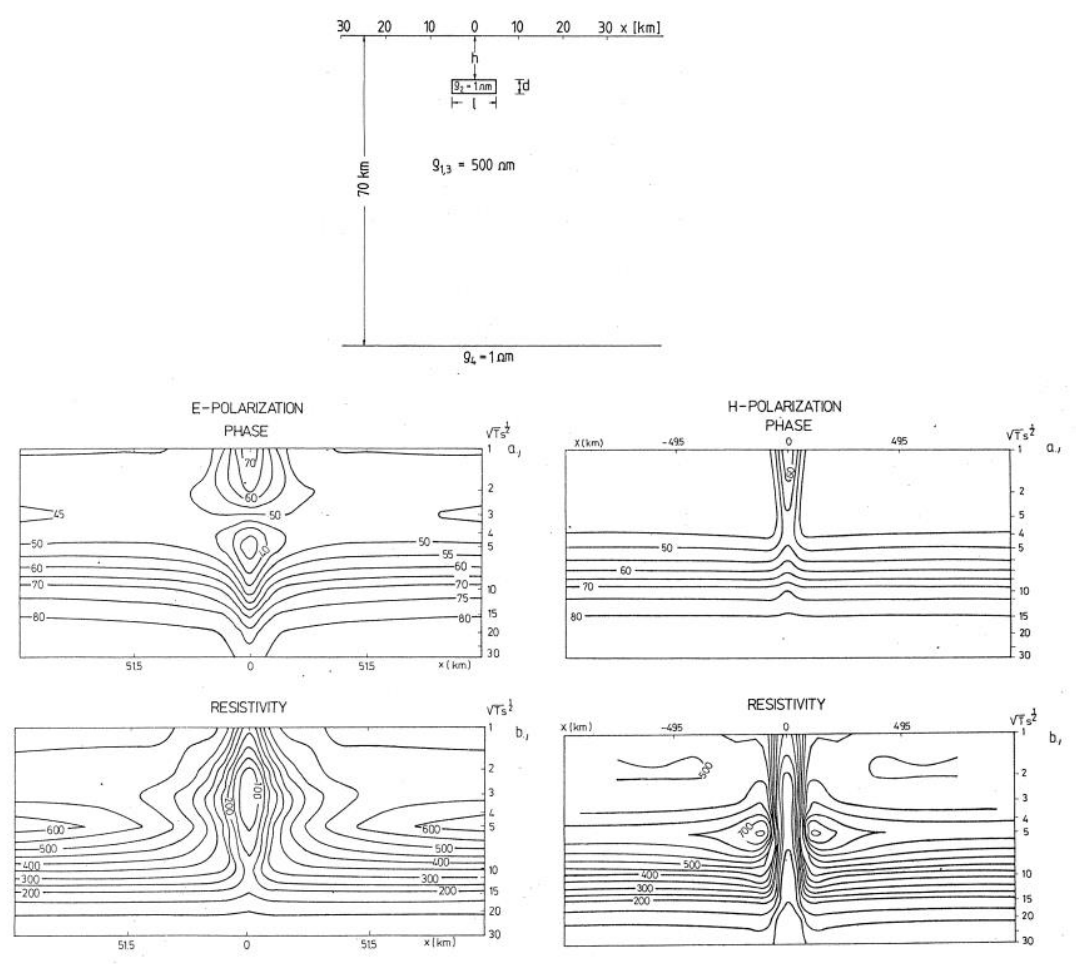

Fig. 3.
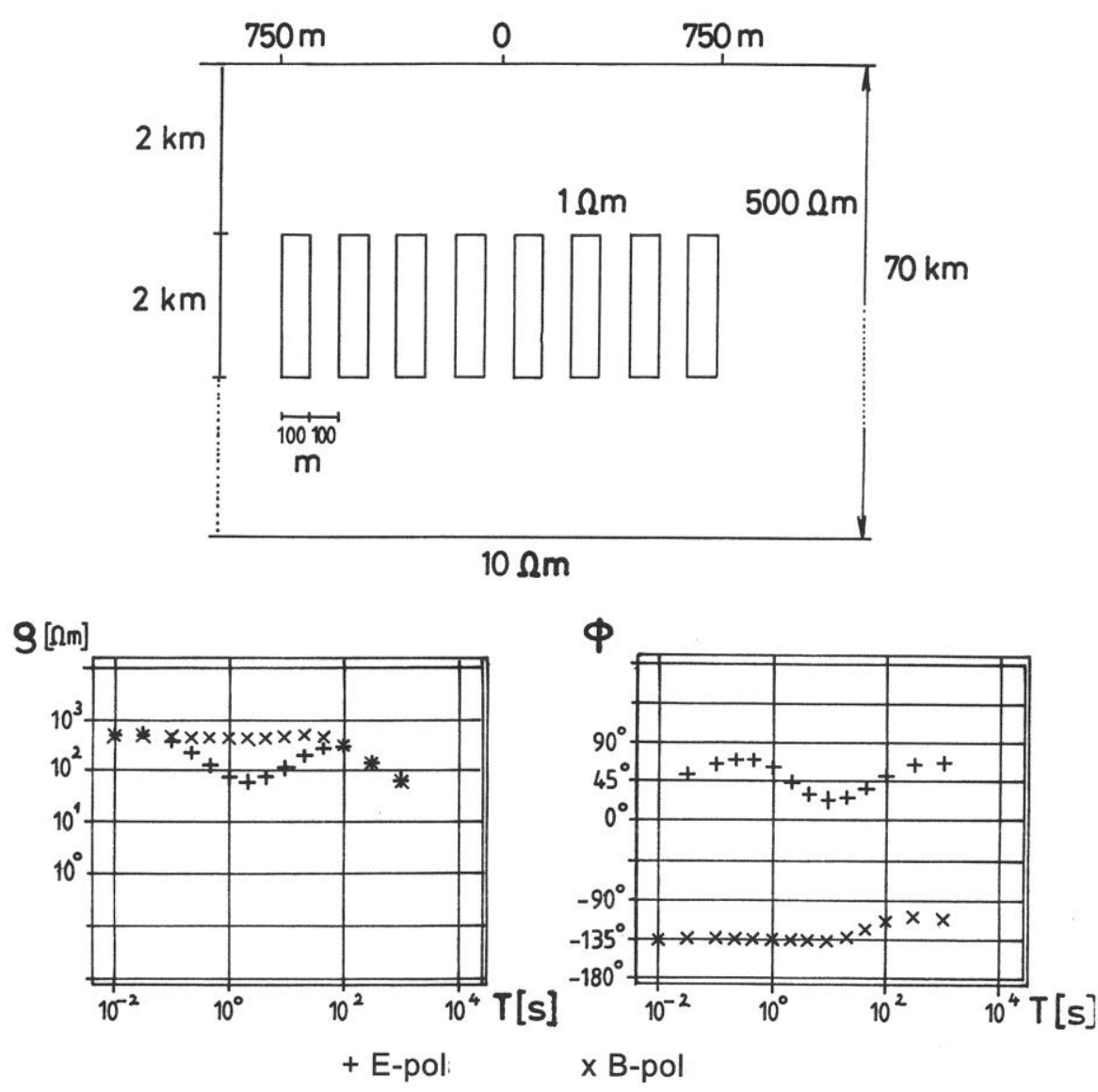

Fig. 4. 

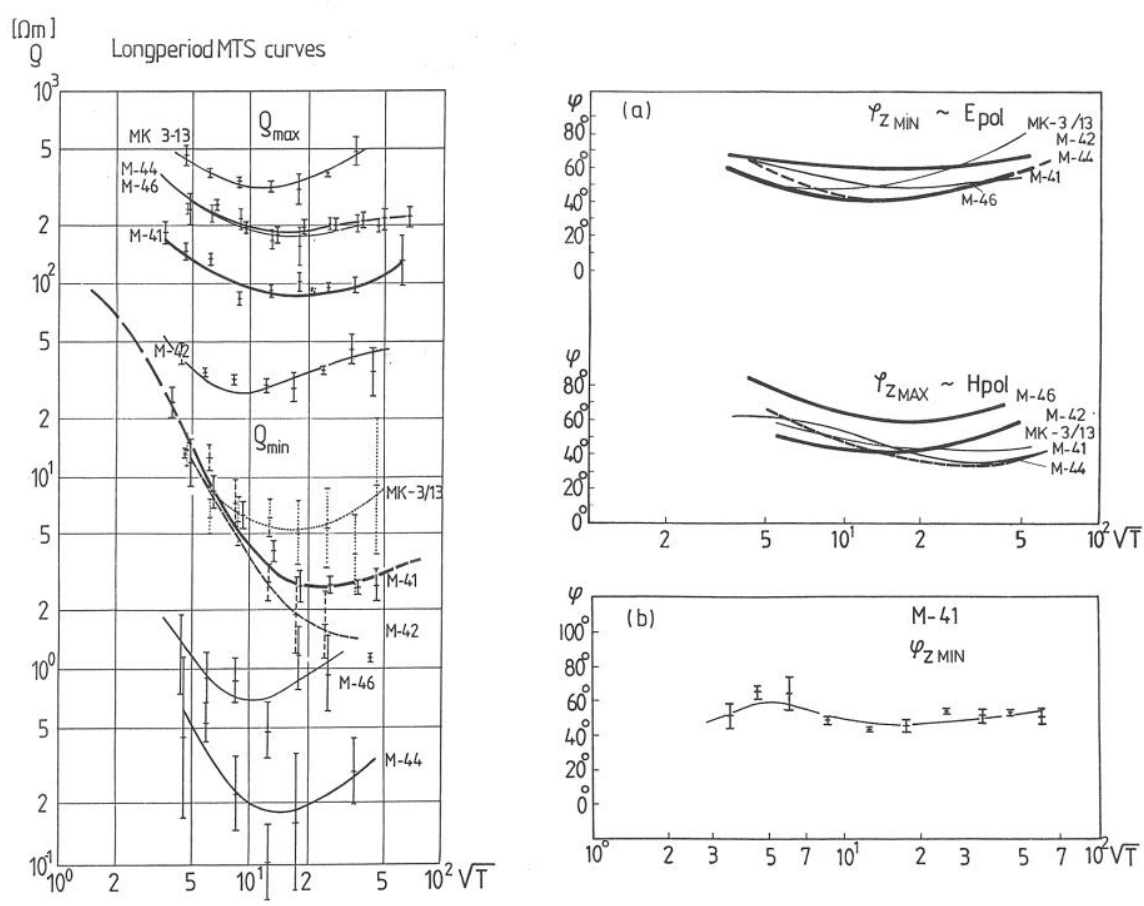

Fig. 5.

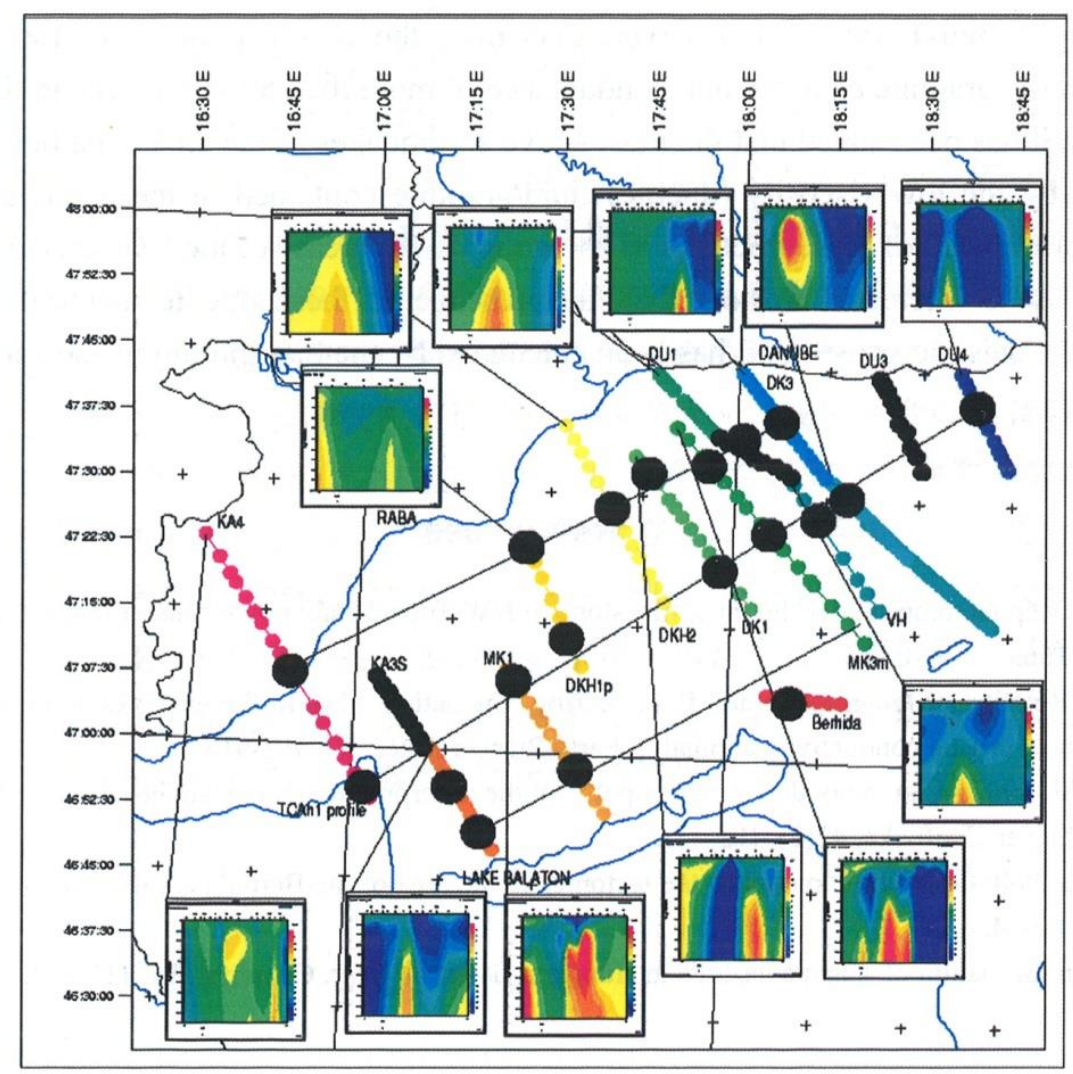

Fig. 6. 


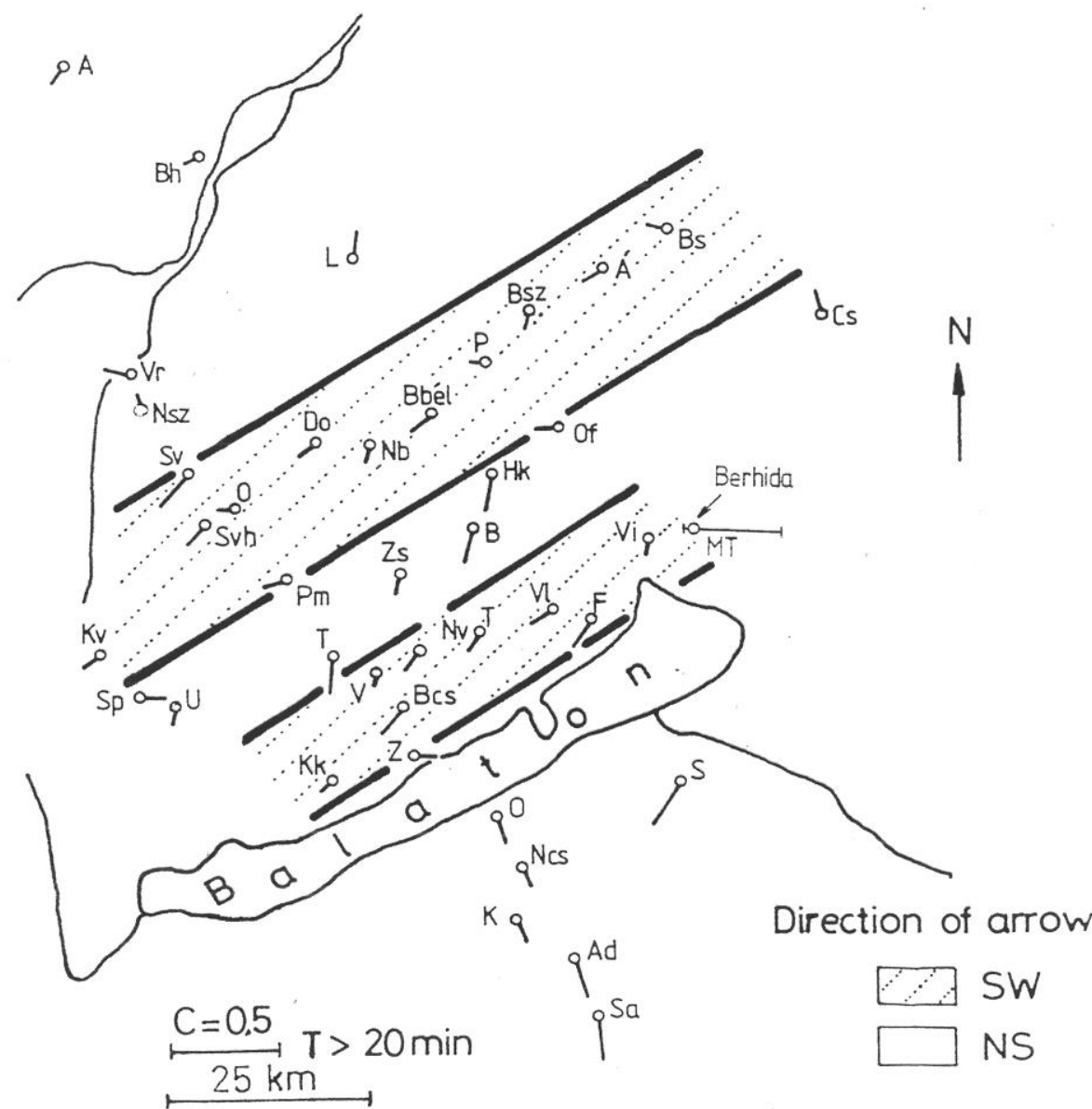

Fig. 7.

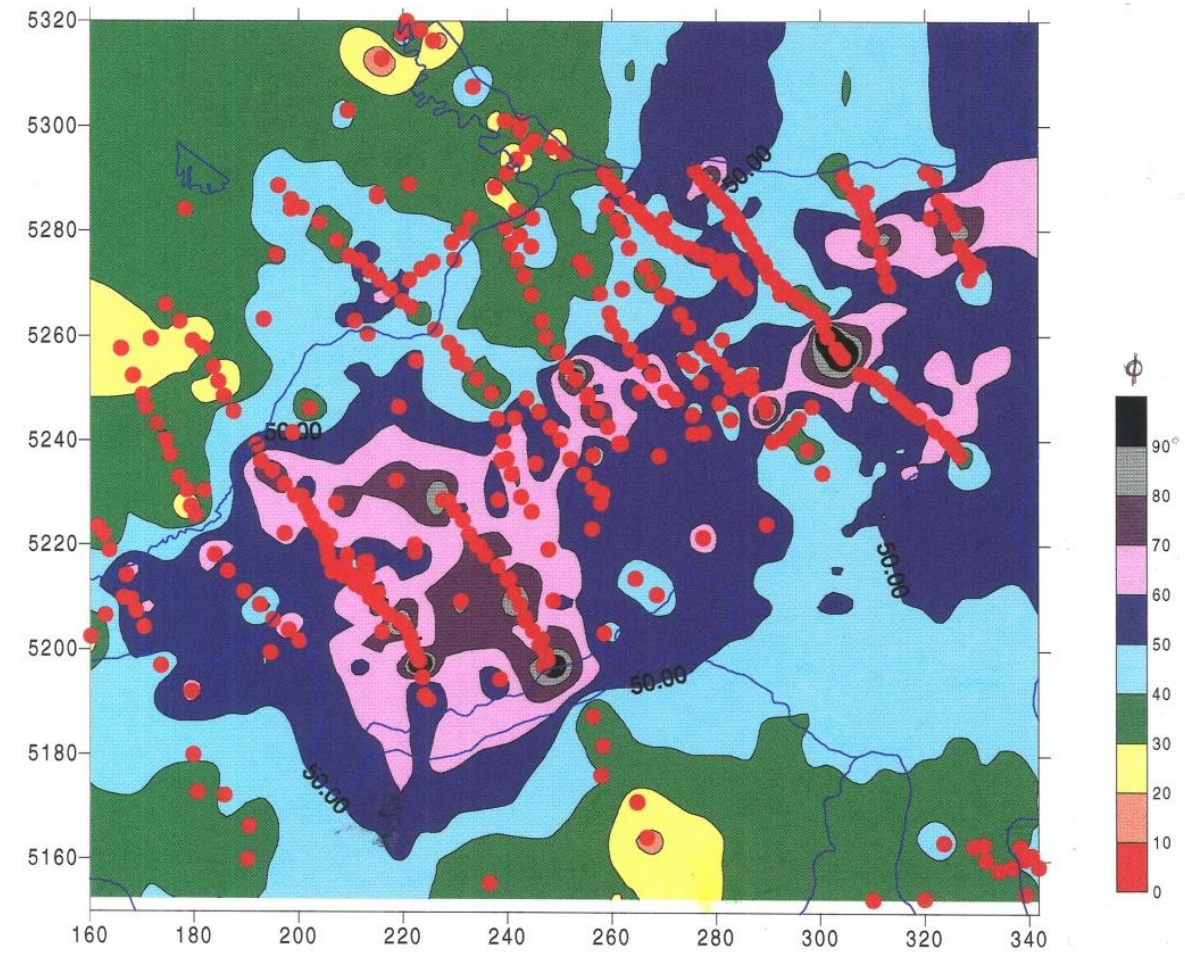

Fig. 8 . 


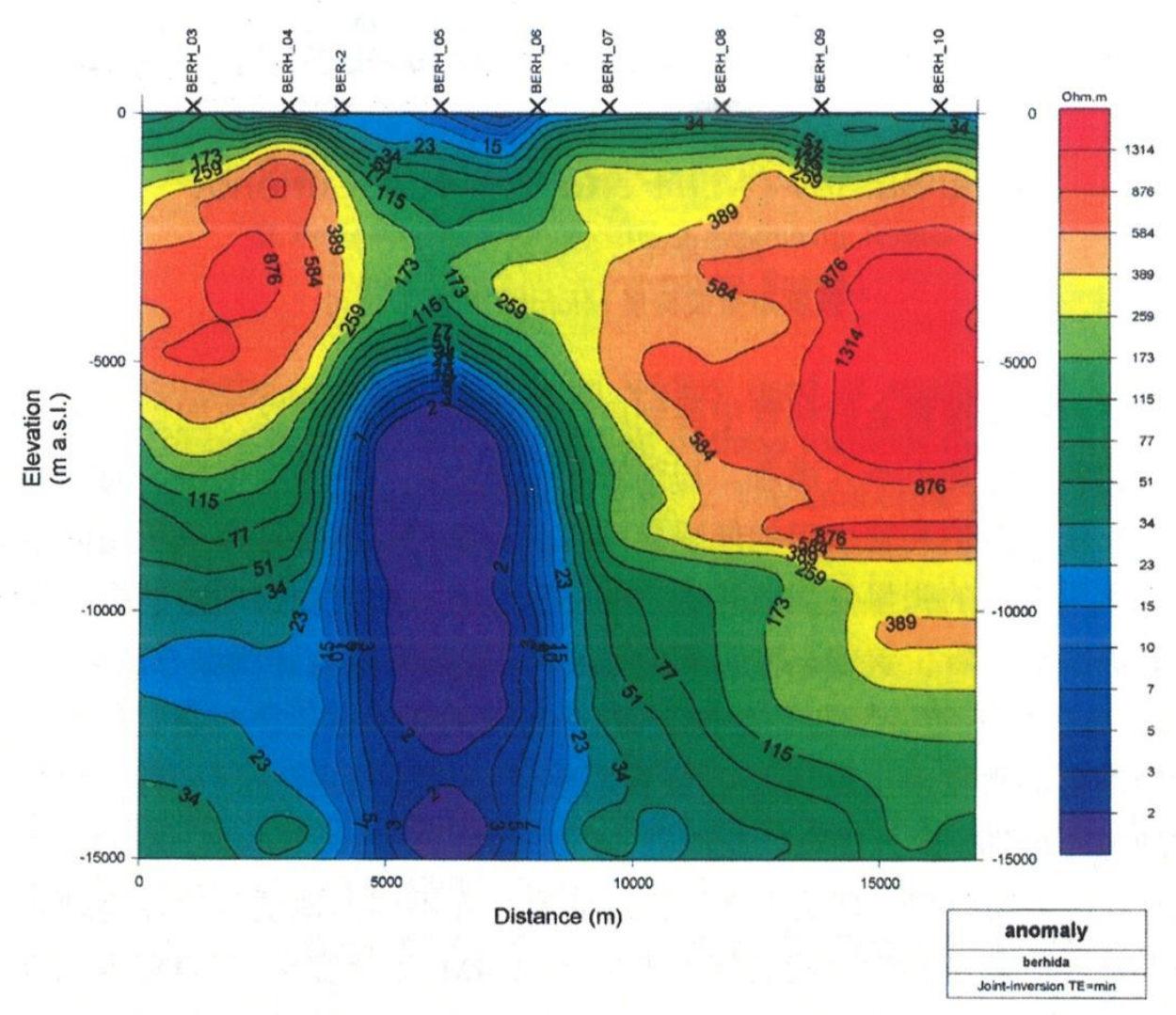

Fig. 9.

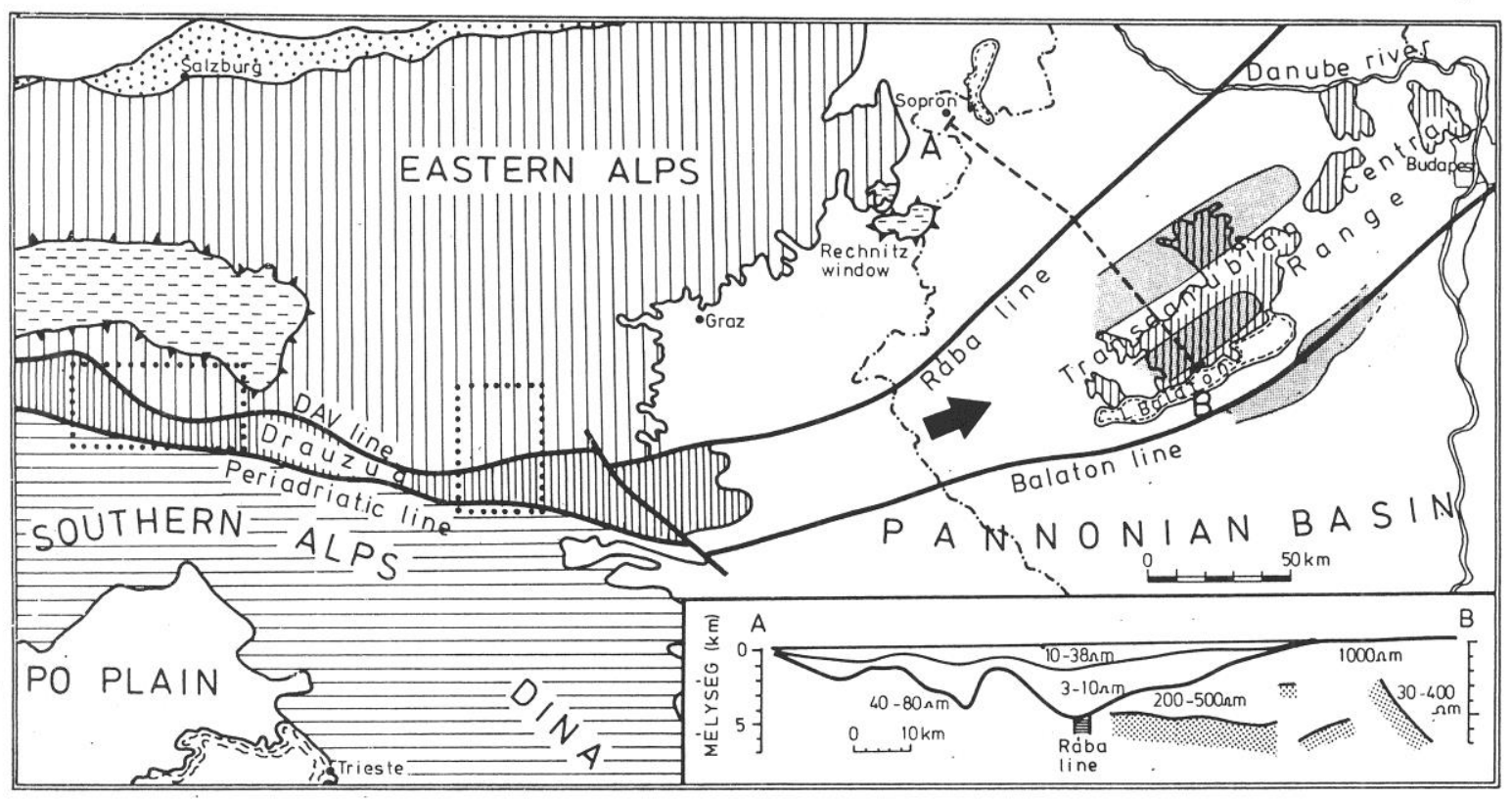

Fig. 10 . 


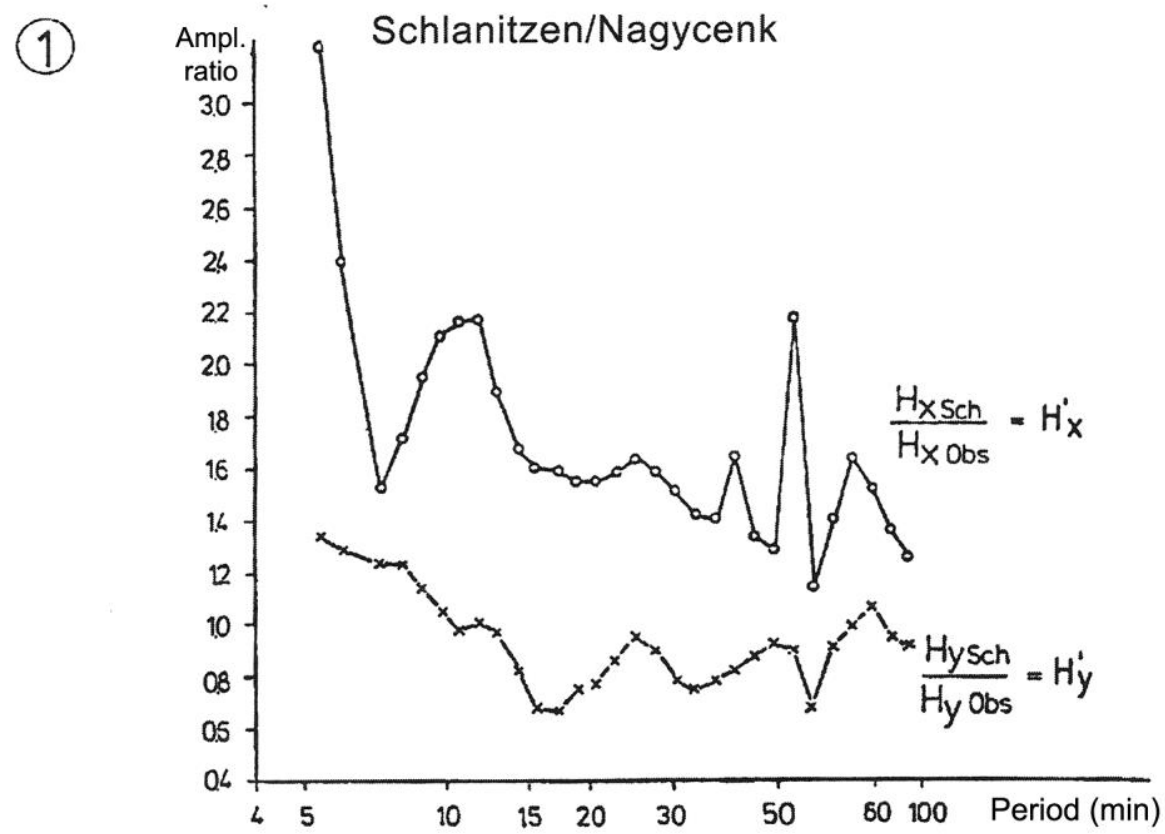

(2) Ampl. Ebriach/Nagycenk

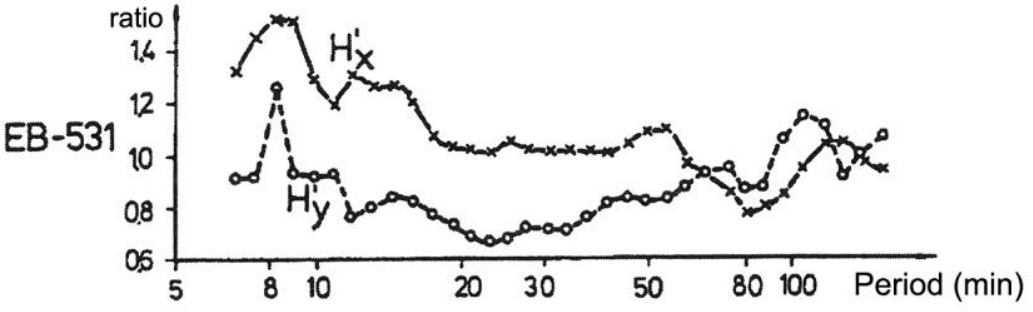

(3) Ampl. Zellpfarre/Nagycenk

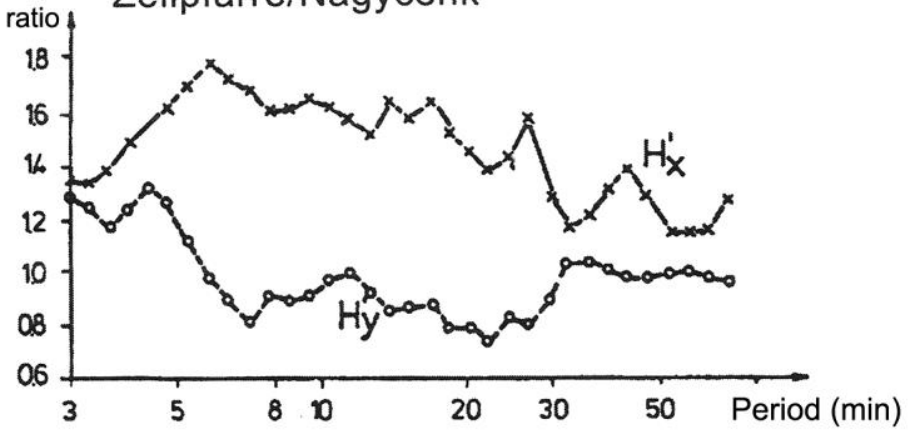

Fig. 11. 


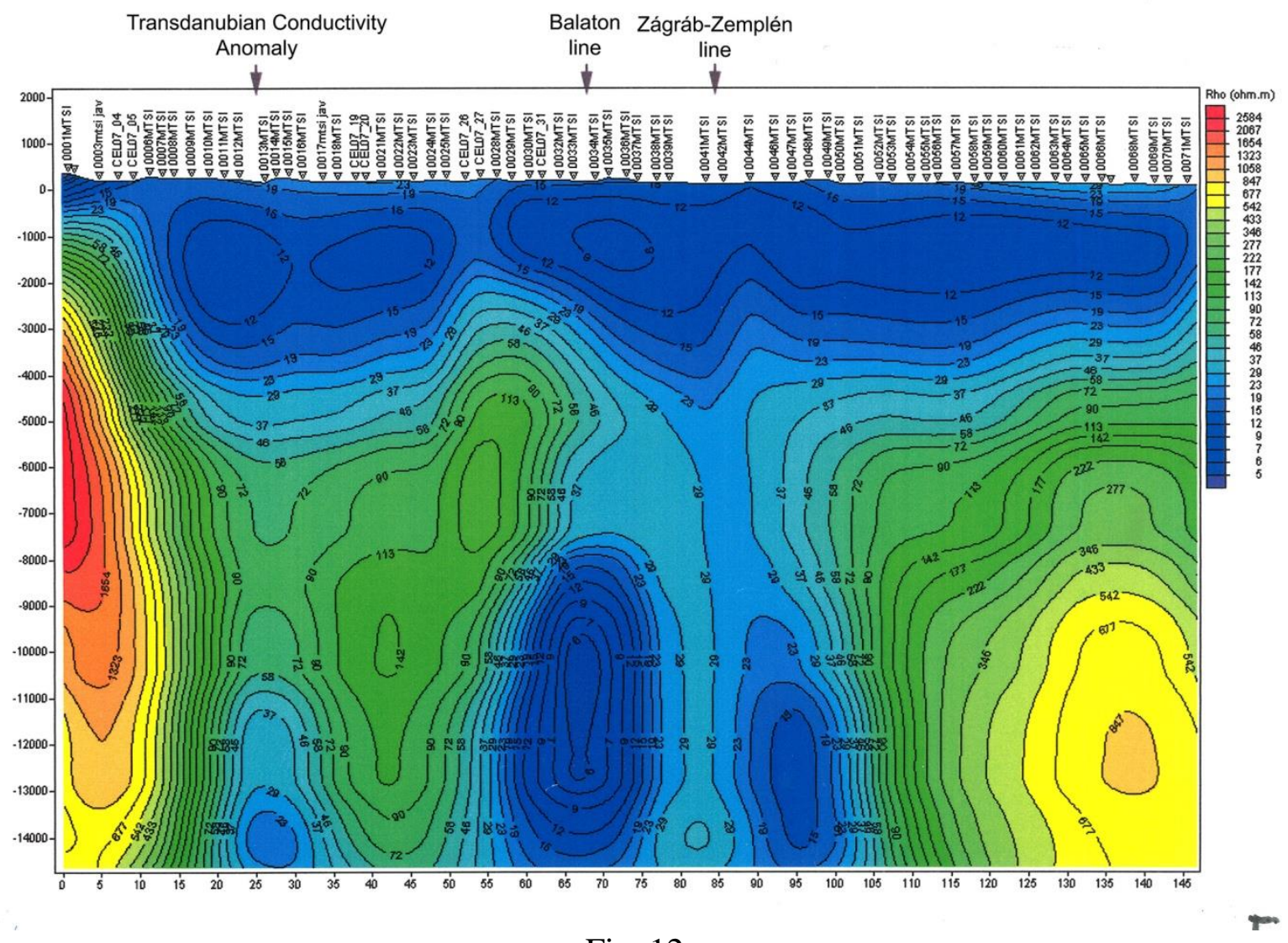

Fig. 12.

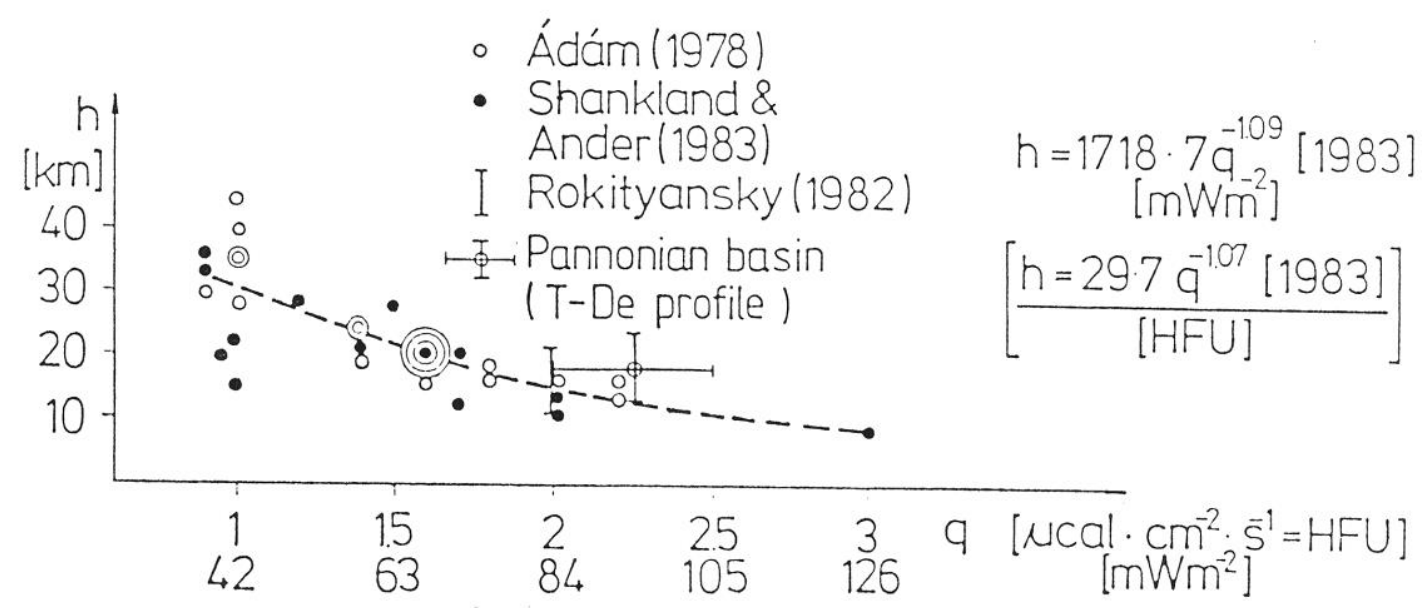

Fig. 13. 


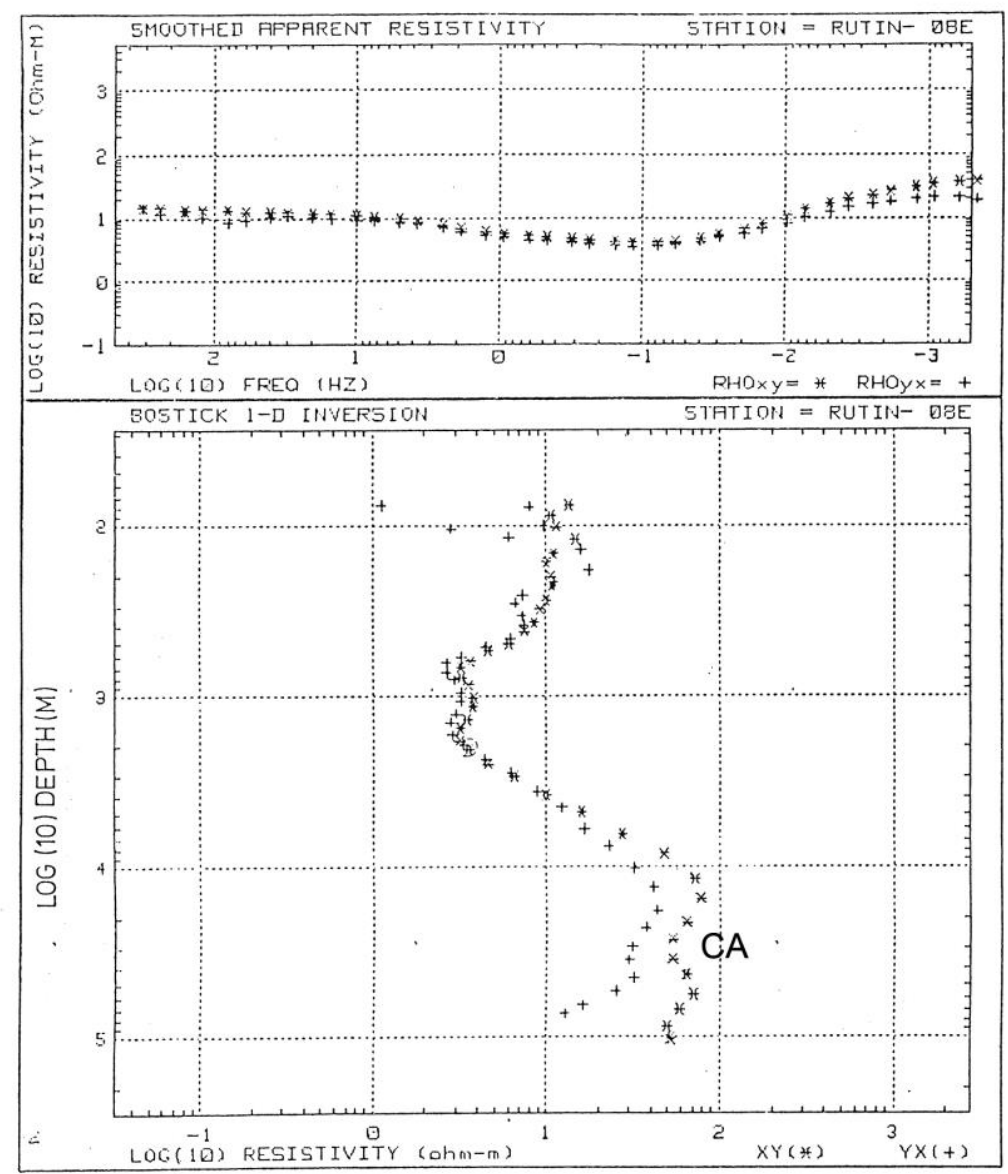

Fig. 14.

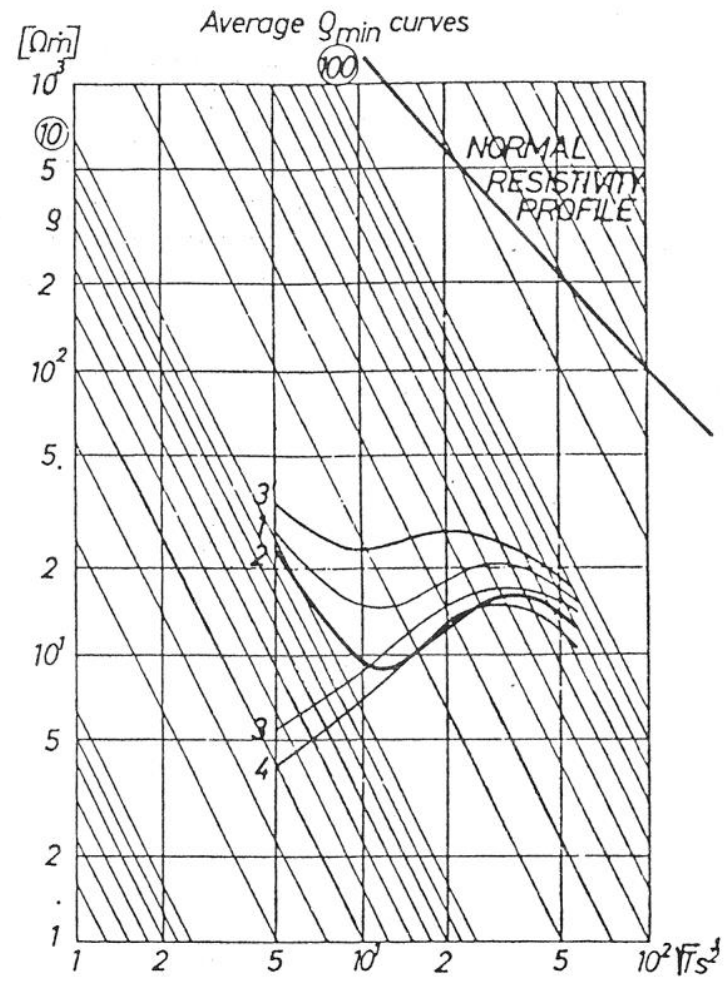

Fig. 15 . 

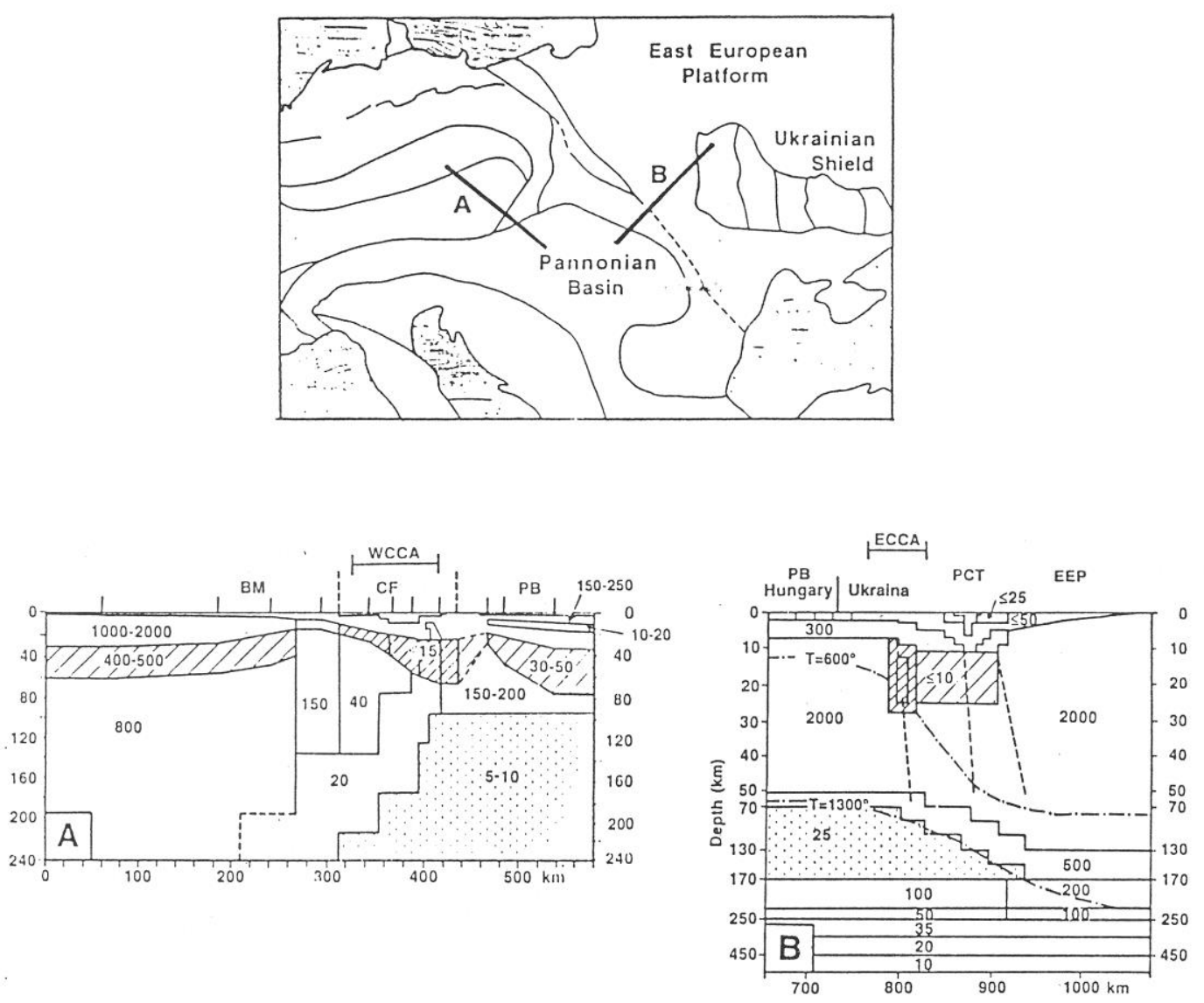

Fig. 16.

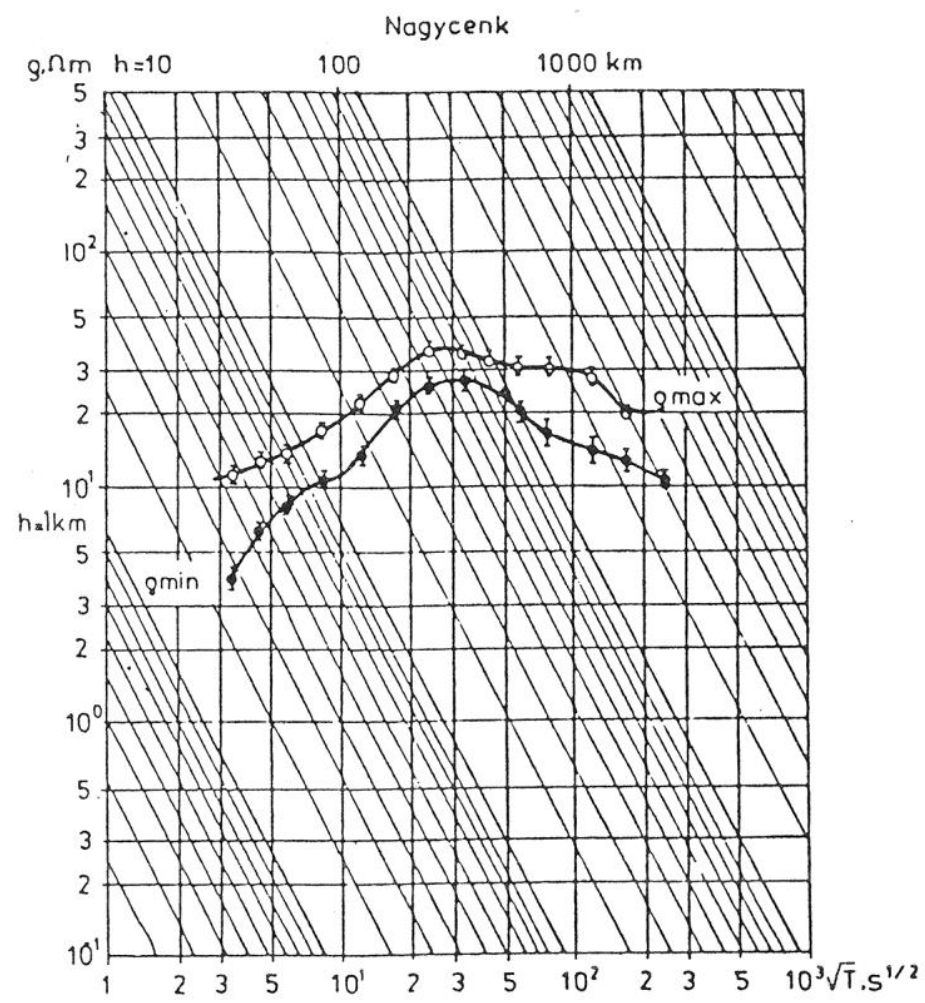

Fig. 17. 


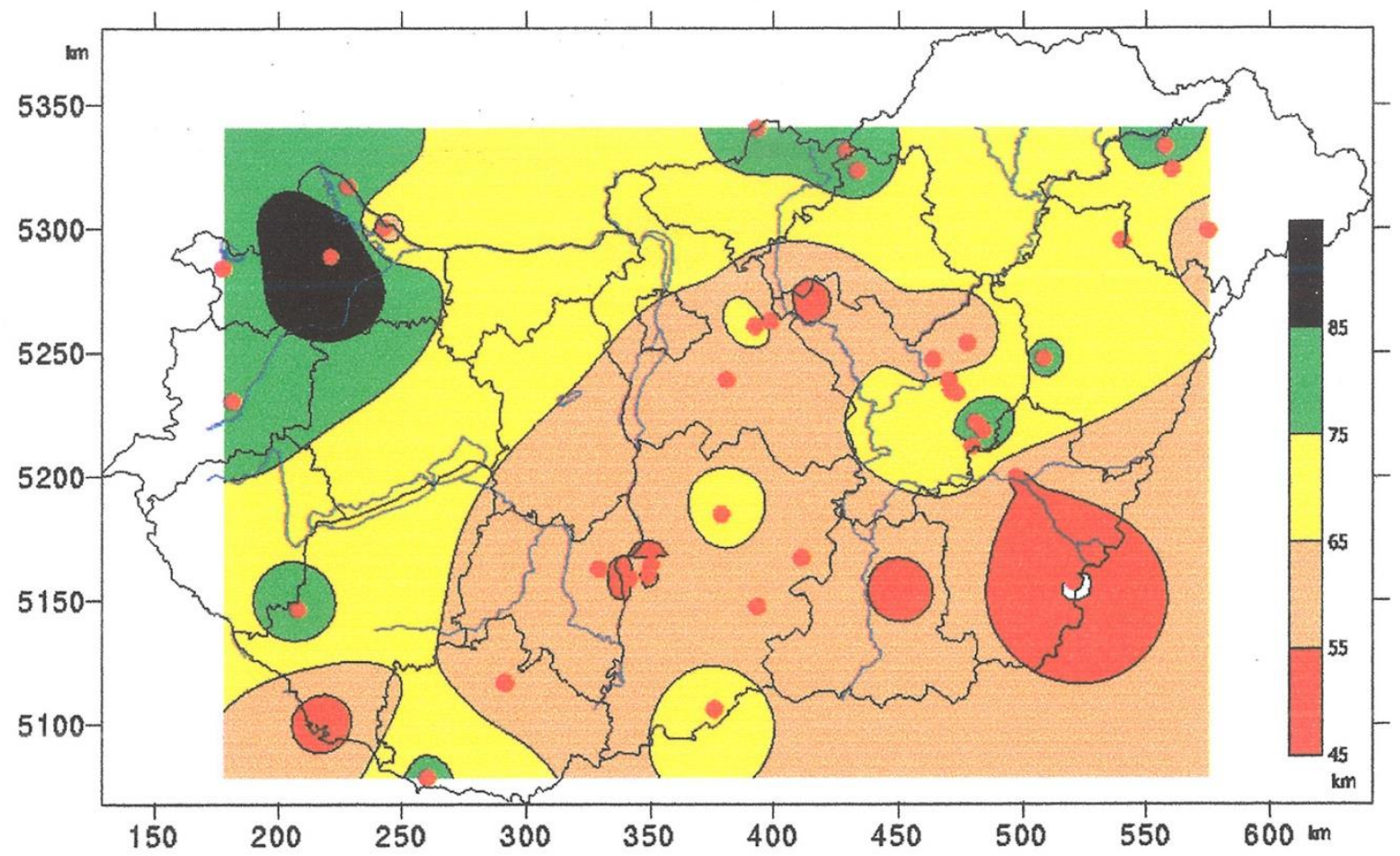

Fig. 18.

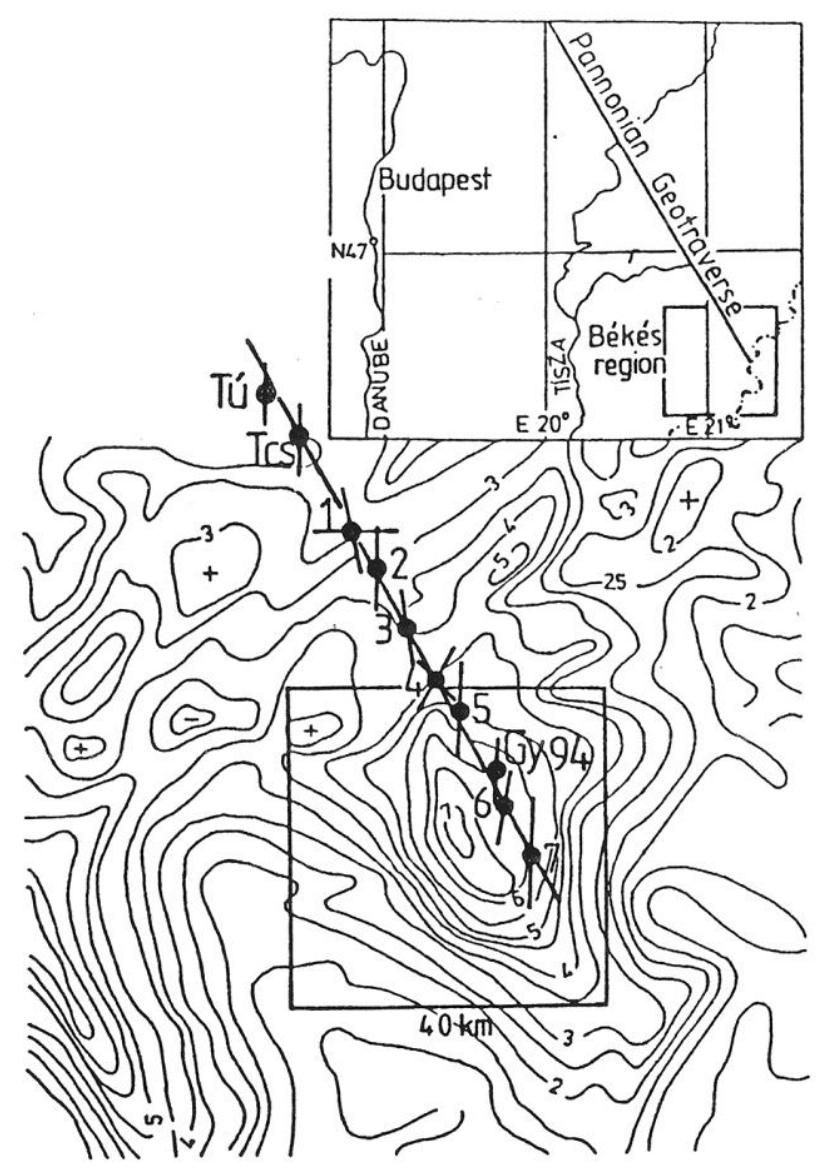

Fig.19. 


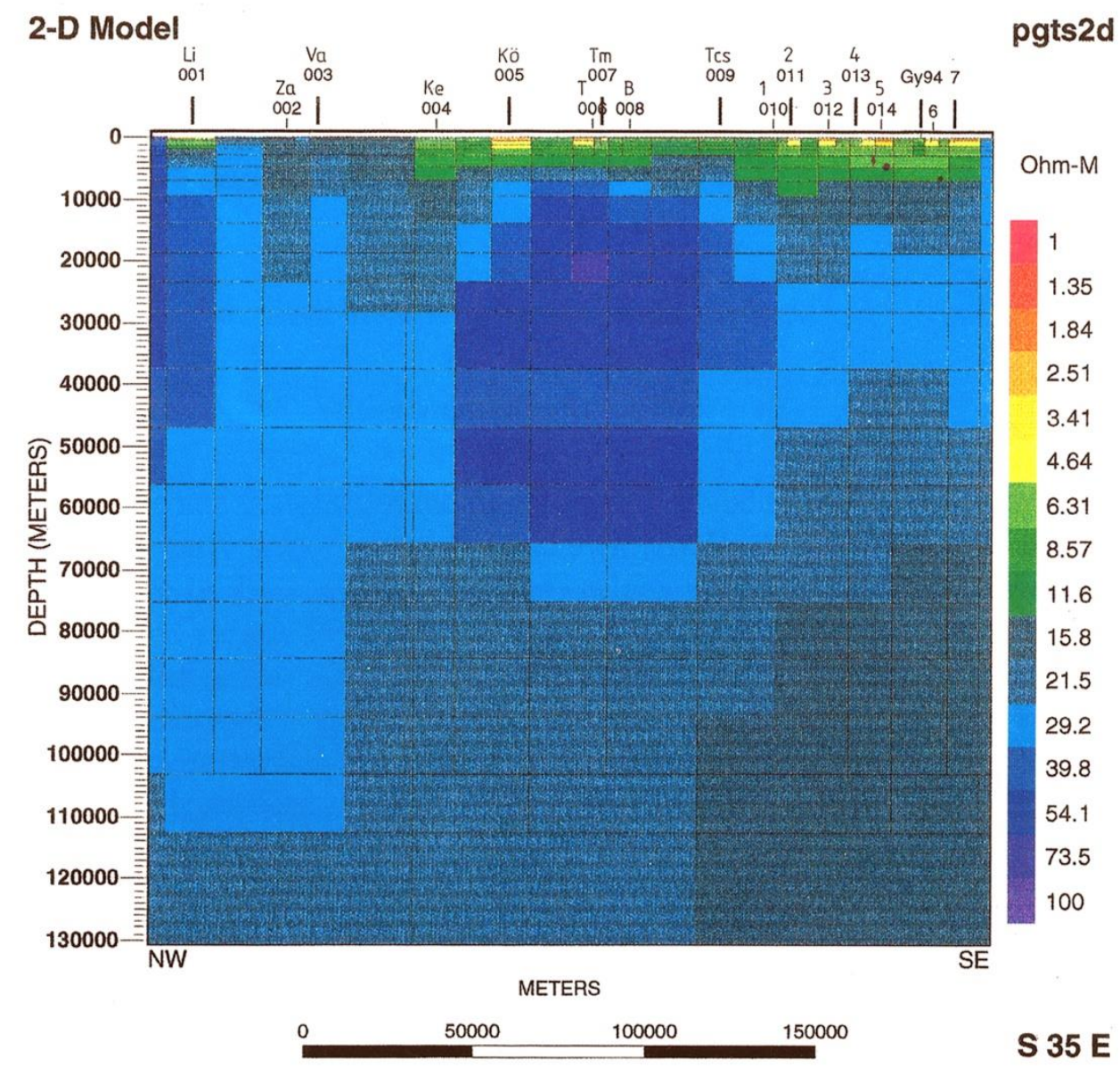

Fig. 20.

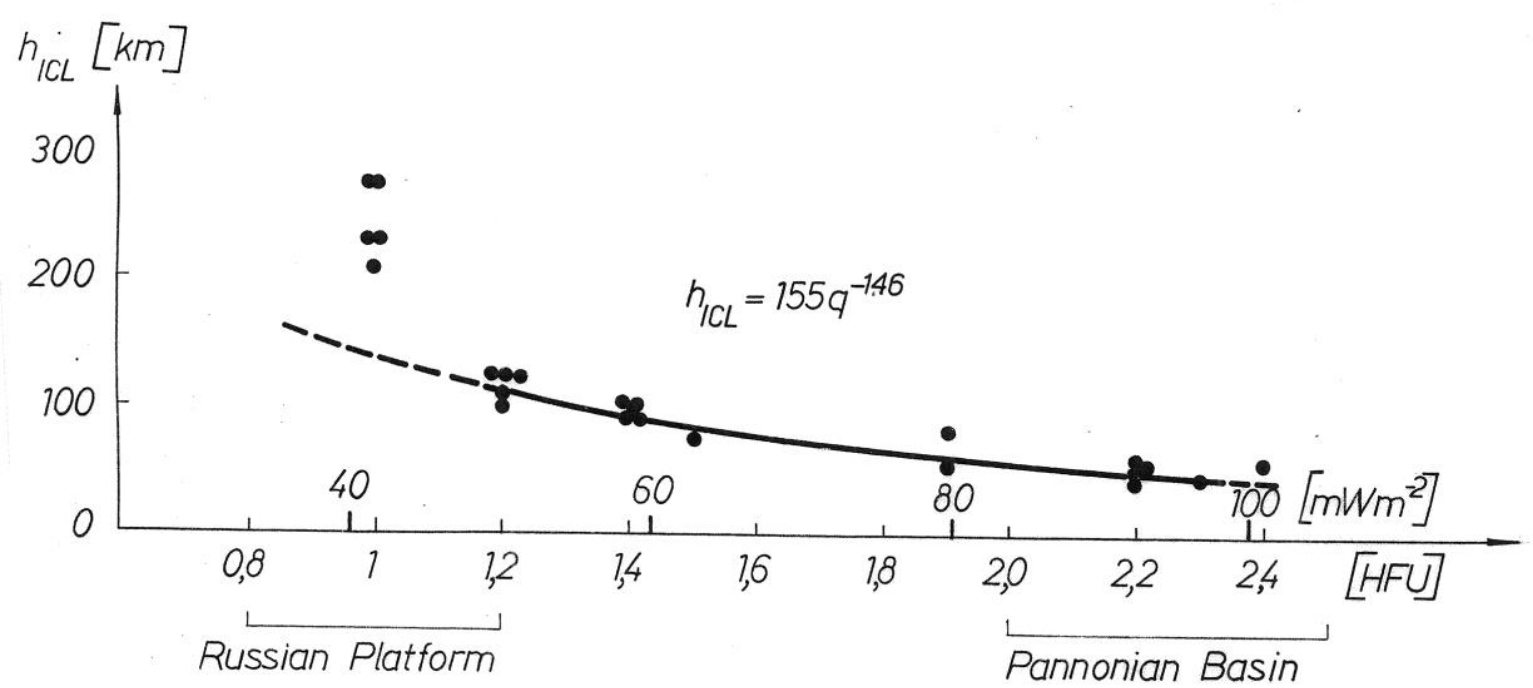

Fig. 21. 